University of Zurich

Department of Economics

Working Paper Series

ISSN 1664-7041 (print)

ISSN 1664-705X (online)

Working Paper No. 379

\title{
Self-serving biases in beliefs about collective outcomes
}

Shimon Kogan, Florian H. Schneider and Roberto A. Weber

March 2021 


\title{
Self-serving biases in beliefs about collective outcomes
}

\author{
Shimon Kogan, Florian H. Schneider and Roberto A. Weber*
}

March 2, 2021

Beliefs about collective outcomes, such as economic growth or firm profitability, play an important role in many contexts. We study biases in the formation of such beliefs. Specifically, we explore whether over-optimism and self-serving biases in information processingdocumented for beliefs about individual outcomes - affect beliefs about collective outcomes. We find that people indeed exhibit self-serving biases for collective outcomes, and that such biases are similar to biases for individual outcomes. In addition, we investigate whether collective selfdelusion is mitigated by market institutions. If anything, biases in information processing are more pronounced in the presence of a market.

Keywords: beliefs, Bayes' rule, asymmetric updating, overconfidence, motivated reasoning JEL Classification: I18, C93, Z13

\footnotetext{
* Kogan: Sloan School of Management, Massachusetts Institute of Technology, and Interdisciplinary Center Herzliya (IDC), skogan@mit.edu. Schneider: Department of Economics, University of Zurich, florian.schneider2@econ.uzh.ch. Weber: Department of Economics, University of Zurich, roberto.weber@econ.uzh.ch. We thank participants at several seminars and conferences for helpful comments.
} 


\section{Introduction}

There is overwhelming evidence that individuals tend to maintain overly positive beliefs about their abilities (e.g. Svenson, 1981; Quattrone and Tversky, 1984), the likelihood of desired future life events (e.g. Irwin, 1953; Weinstein, 1980; Mayraz, 2013) and their own morality (e.g. Bénabou and Tirole, 2016; Gino, Norton and Weber, 2016). Such over-optimism often appears to result from biases in how people acquire and process information: individuals avoid information that challenges their overly positive beliefs (e.g. Dana, Weber and Kuang, 2007; Oster, Shoulson and Dorsey, 2013; Ganguly and Tasoff, 2017), update less in response to bad news than to good news (e.g. Eil and Rao, 2011; Möbius et al., 2017), and are less likely to remember negative past signals than positive past signals (Zimmermann, 2020; Saucet and Villeval, 2019). Such biases are supported by the psychological and motivational benefits from optimism and maintaining a positive self-image (Akerlof and Dickens, 1982; Rabin, 1994; Brunnermeier and Parker, 2005; Bénabou and Tirole, 2006 and 2011; Bénabou, 2013).

Most existing work on over-optimism and self-delusion focuses on beliefs about desirable individual outcomes. However, in many important economic contexts, people have to form beliefs about collective outcomes, such as future economic growth, firm profitability or success in containing the outbreak of a pandemic. ${ }^{1}$ As with the benefits from maintaining a desirable self-image, people may often be motivated to maintain beliefs that collective outcomes will also be positive. For example, individuals may benefit psychologically and may be motivated to engage in productive activities like work and investment when they believe that future economic conditions will be positive. Similarly, employees in a firm may find it desirable and motivating to believe that the company is and will continue to perform well. The same motives that underlie self-delusion regarding individual outcomes could, therefore, also affect information processing about collective outcomes. This could, in turn, yield important economic consequences, as collective over-optimism and wishful-thinking about the price growth of widely held assets are believed to play an important role in the formation of speculative bubbles

\footnotetext{
${ }^{1}$ Multiple studies provide evidence that beliefs about macroeconomic expectations matter for economic decision making (e.g., Armona, Fuster and Zafar, 2019; Roth and Wohlfart, 2020; Andre et al, 2019). There is some previous work that investigates the role of personal experience in belief formation for collective outcomes (Malmendier and Nagel, 2011, 2016; Kuchler and Zafar, 2019; Cotofan, Cassar, Dur and Meier, 2021).
} 
(Shiller, 2002; Foote, Gerardi and Willen, 2012; Cheng, Raina and Xiong, 2014) and in explaining market anomalies such as the equity home bias puzzle (Strong and $\mathrm{Xu}, 2003)^{2}{ }^{2}$

In this paper, we study whether self-serving biases in information processing exist for beliefs about collective outcomes, and directly compare them to the beliefs that agents form over individual outcomes. ${ }^{3}$ A challenge in investigating this question using naturally occurring collective outcomes is that the information generating process in such contexts is typically unknown, and, as a consequence, we do not know the rational benchmark for belief updating. To overcome this challenge, we design a laboratory experiment in which we can construct the information generating process and hold key aspects of it fixed when comparing belief updating for collective outcomes with belief updating for individual outcomes. We find that participants exhibit self-serving biases for collective outcomes, and that biases are remarkably similar to biases for beliefs about individual outcomes. We thereby provide important evidence that motivated reasoning matters for the formation of beliefs about collective outcomes.

In our experiment, subjects perform a task based on reasoning ability, with their relative performance determining whether or not they receive a monetary prize. After completing the task, individuals receive noisy signals about their relative performance. We elicit their beliefs about relative performance, both before and after receiving the noisy signals. By relying on individual ability, this task creates the conditions that have been found to give rise to self-serving information processing, whereby positive information is over weighted relative to negative information (Eil and Rao, 2011; Möbius, et al., 2017).

In our first principal treatment condition, Individual, participants work independently on the above task. Each individual is matched with another participant, and relative individual performance on the task in the pair determines who wins a monetary prize. We elicit participants' beliefs of the relative likelihood that they outperformed their competitor, both before and after providing them with a noisy signal of their relative performance. The Individual

\footnotetext{
${ }^{2}$ There is some suggestive evidence that motivated beliefs might affect market outcomes. Strong and Xu (2003) show that-in line with wishful thinking - fund managers are significantly more optimistic towards their home equity market. Cheng, Raina and Xiong (2014) present evidence on the role of overconfidence in financial crises. Ma (2015) find that banks with CEOs who were more optimistic about future payoffs of housing investments had worse crisis performance. Collective self-delusion is also believed to affect corporate behavior. Anecdotal evidence suggests that collective denial of unethical and illegal business practices played a role in corporate scandals (Anand, Ashforth and Joshi, 2005; Bénabou, 2013).

${ }^{3}$ A recent paper, somewhat related to ours, investigates how individuals' beliefs are influenced by observing the beliefs of other individuals of similar (true) ability (Oprea and Yuksel, 2020). They find that exposure to such beliefs increases the degree of positivity bias. A key difference between our studies and theirs is that we directly investigate beliefs over collective outcomes, while their study retains a focus on beliefs about individual ability.
} 
condition provides us with a benchmark of self-serving biases in forming and updating beliefs about individual outcomes. Consistent with earlier work, we find both initial overconfidence and evidence of asymmetric updating - with individuals overweighting positive signals relative to negative ones-for beliefs about individual outcomes. While not the main focus of our project, this replication is of interest in itself as there is conflicting evidence on the existence of asymmetric updating (Buser, et al., 2018; Coutts, 2019; Schwardmann and Van der Weele, 2020; Oprea and Yuksel, 2020). ${ }^{4}$

Our main alternative condition, Collective, is identical except that the task and relative beliefs now involve the performance of six-person groups. Group members perform the task together, submitting a common response, and communicate with each other via a chat box. Each group competes with another six-person group, with the higher-performing group obtaining a prize. Hence, whether or not the group outperforms the other group is a collective outcome, determined by the joint performance of group members. We elicit incentivized beliefs about the group's relative performance, both before and after providing a noisy signal.

Our results provide clear evidence of self-serving biases in the formation of collective beliefs. We document such biases in two ways. First, the priors reveal that subjects exhibit overconfidence over collective outcomes. Second, we find that subjects update their beliefs asymmetrically, that is, they update less in response to bad news about their group's relative performance than to good news. Moreover, we also document other biases in the formation of beliefs about collective outcomes that are also present in the formation of beliefs about individual performance. For example, we find that subjects exhibit substantial conservatism when updating beliefs about collective performance - that is, they do not react as strongly to signals as they should according to the rational (Bayesian) benchmark - and base-rate neglect. All of the above biases are qualitatively similar to those we observe in the Individual condition. We thus conclude that biased information processing exists for collective outcomes in a manner similar to how it occurs for individual outcomes.

\footnotetext{
${ }^{4}$ Eil and Rao (2011), Sharot, Korn and Dolan (2011), Garrett and Sharot (2014), and Wiswall and Zafar (2015) find evidence for asymmetric updating. Ertac (2011) find that people put more weight on negative signals. These studies differ substantially from the Möbius et al. (2017) framework, making comparisons across studies challenging. Cacault and Grieder (2019) find evidence for asymmetric updating about others' ability. Coutts, Gerhards and Murad (2020) investigate self-attribution bias in the context of belief updating. Barron (2021), Coutts (2019) and Gotthard-Real (2017) look at updating of non-ego-relevant information, and find no asymmetric updating.
} 
We also conduct an additional treatment condition to investigate whether an informationaggregation institution, such as a market, influences the formation of collective self-delusion. Self-delusion about collective outcomes might be particularly important in market contexts, such as asset trading. While individual biases might be mitigated by the collective judgment produced in markets (Camerer, 1987; Camerer et al., 1989; Forsythe et al., 1992), market interactions with others that have similar motives for self-deception could also reinforce biased beliefs (Shiller, 2002; Seybert and Bloomfield, 2009; Kogan, Kwasnica and Weber, 2011; Bénabou, 2013).

The Market condition is identical to Collective, except that after subjects receive feedback regarding their group's relative performance, they participate in an asset market in which they trade assets with the other members of their group. Each asset pays a positive dividend if their group wins the competition, but no dividend if their group loses the competition. This reflects a market situation where traders may engage in wishful-thinking about the value of an asset, either because they are financially committed to it (Shiller, 2002) or because they are elsewise affected by the profitability of the issuer, for example in the case of assets from a major local employer. After subjects have participated in the market, we elicit beliefs about their group's relative performance.

We find that market prices depart substantially from fundamentals, reflecting overconfidence, asymmetric updating, and reluctance to bet against the occurrence of desired outcomes. This suggests that collective self-delusion might indeed play an important role in market contexts. More importantly, we do not find that markets mitigate biases in information processing. If anything, we find that the market institution exacerbates biases: compared to the Collective condition, subjects underreact even more to bad signals in the Market condition than in the Collective condition, resulting in higher degrees of asymmetric updating.

Our findings add an important dimension to the growing body of evidence on the formation of self-serving beliefs. Given the widespread relevance of beliefs about collective outcomes, our findings that self-serving biases in belief formation extend to collective settings and that markets do not seem to substantially mitigate these biases are important.

The next section provides a detailed description of the design of our study. In Section 3, we present our results. Finally, section 4 concludes. 


\section{Study design}

Our design builds on the framework of Möbius et al. (2017). In each round of the experiment, individuals, or groups, first compete by performing a task and then submit beliefs about their relative performance in this task. Next, they receive a noisy signal about their relative performance and submit their updated beliefs. The above steps are repeated in four rounds. ${ }^{5}$

This context allows us to investigate both overconfidence and updating behavior in response to good and bad signals. To study how overconfidence and biased information processing differ for individual and group outcomes, we manipulate whether the task and beliefs are about individual performance or collective performance. We also conduct an additional treatment in which we introduce a market to study how this institution influences the formation of collective beliefs.

\subsection{The Task}

At the beginning of the experiment, directly after groups are formed (in the Collective and Market conditions), each individual/group is randomly matched with another individual/group. This pairing is constant across the four rounds.

Across all treatment conditions (described below) and rounds of the experiment, subjects are first asked to work on solving a knapsack problem (Murawski and Bossaerts, 2016; Tang, et al., 2017) in a limited amount of time. Knapsack problems consist of deciding which objects in a finite set to select (i.e., to "put into the knapsack"). Each object has a value and a weight. The goal is to choose the set of objects that maximize the total value subject to some weight constraint:

$$
\max _{x_{i} \in\{0,1\}} \sum_{i}^{I} v_{i} x_{i} \quad \text { s.t. } \sum_{i}^{I} w_{i} x_{i} \leq C
$$

where $I$ is the total number of objects, $v_{i}$ is the value of object $i, w_{i}$ is the weight of object $i$ and $C$ is the weight constraint. Finding the optimal solution is a combinatorial optimization problem that has no single solution approach. More formally, these problems are NP-hard, which means that no know algorithm solves these problems in an efficient manner as the size of the problem increases. ${ }^{6}$ Practically, that means that there is no approach that ensures an optimal solution of

\footnotetext{
${ }^{5}$ In the design of Möbius et al. (2017), subjects receive multiple signals for each task and therefore repeatedly update their beliefs. We opt for only one belief update per task to decrease the number of markets in the Market condition.

${ }^{6}$ Efficient means that computational time increases in polynomial time as the size of the problem increases.
} 
these problems across all instances. For example, the intuitive approach of calculating the value/weight ratio of each object and then inserting objects into the knapsack in descending order until the weight capacity is reached results in an optimal solution in some but not all problem instances.

The experiment introduced knapsack problems with differing levels of difficulty in random order across rounds. We chose these knapsack problems for several reasons. First, they are easy to explain to subjects. Second, knapsack problems allow a group of subjects to collaborate electronically. Finally, given that there is no global solution approach and many possible permutations, it is difficult for subjects to verify whether they have a "correct" answer. If, instead, subjects could easily verify whether they submitted an optimal response, beliefs regarding relative performance would be less clear in such cases. Finally, each instance of the problem presents a new challenge in which earlier solutions may not be helpful, meaning that there is some independence of performance across rounds.

In the Individual condition, subjects work independently on the knapsack problem on their computer screen. They observe the parameters for that specific problem, can click on items to include in the knapsack and observe the score of their current selection. The interface also records the best solution found thus far, allowing subjects to easily implement this solution. Figure $\mathrm{C} 1$ in the Appendix provides an example of the interface employed when working on the task.

In both the Collective and Market conditions, subjects are randomly organized into groups of six and work jointly on one knapsack problem, submitting one final solution for the group. Subjects see the current knapsack problem on their screen and can search for solutions. When they find a promising solution, they can share it with the other members of their group. Subjects observe the best solution found yet by any of their group members. To facilitate collaboration, subjects can communicate via a chat interface with their teammates. This communication includes free text as well as proposed solutions to the knapsack problem. Figure C2 in the Appendix provides an example of the interface employed when solving the task. Group composition is constant across the four rounds. The only difference between the Collective and the Market conditions is the information subjects receive between rounds, which we explain later. 
Across all conditions, subjects get 90 seconds to initially inspect the knapsack problem for that round and 60 additional seconds to try out different solutions. In the Collective and Market conditions, subjects can communicate with their group members during the full 150 seconds.

\subsection{Incentives, beliefs and markets}

In the Individual condition, participants who provide a better solution than their matched counterpart receive $40 \mathrm{CHF}(\approx \$ 40)$ while those with the inferior solution receive $10 \mathrm{CHF}$. Given the discrete nature of the solution, ties are resolved by observing the time it took to submit the final (best) solution. The Collective and Market conditions generate the same per-person payoffs from providing an inferior or a better solution in the knapsack problem: the group that provides the better solution receives $240 \mathrm{CHF}$ (paid in equal shares to each member) while the group with the inferior solution receives $60 \mathrm{CHF}$.

Next, subjects are asked to report their belief, $p$ (on a scale of $0-100$ ), that their solution is better than that of the matched individual or group. We incentivize accuracy with a quadratic scoring rule: ${ }^{7}$

$$
\text { Payment }(\text { in } C H F)=10-10 *\left(\mathbf{1}(\text { better })-\frac{p}{100}\right)^{2}
$$

where $\mathbf{1}$ (better) equals 1 if a subject's solution is better in that round (and 0 otherwise) and $p$ is the probability estimate.

After submitting the first confidence report, subjects receive a signal about their relative performance in that round. In the Individual condition, the signal (\{negative,positive $\}$ ) is drawn from a distribution that reveals the true relative performance in that round with $2 / 3$ probability and gives the wrong relative performance with $1 / 3$ probability. The same signal is drawn, at the group level, in both the Collective and Market conditions; all members of a group receive the same signal. ${ }^{8}$

\footnotetext{
${ }^{7}$ Möbius et al. (2017) and the subsequent literature use the probabilistic crossover method (also called matching probabilities) to incentivize the belief elicitation. This method, however, potentially depends on ambiguity attitudes and the ambiguity of the event evaluated (see e.g. Baillon, Cabantous and Wakker, 2012). In our experiment, we worried about potential differences between treatment conditions in ambiguity about relative performance, so we therefore chose a quadratic scoring rule instead. This rule is also easy to explain to participants.

${ }^{8} \mathrm{We}$ explain to subjects that there is an urn with 3 balls: 2 balls correspond to the participant (group) that won and 1 ball corresponds to the participant (group) that lost. We explain that 1 ball is drawn from the urn, and both the subject (group), and the
} 
In the Market condition, subjects next participate in a double-auction asset market. ${ }^{9}$ Each group forms an independent market; that is, subjects trade assets within their group. The group trades a single Arrow-Debreu security that pays off $2 \mathrm{CHF}$ if the group obtained the better knapsack solution in that round and $0 \mathrm{CHF}$ otherwise. Subjects' security endowments in the market session are designed to add up to zero, as to neutralize aggregate incentive effects from the market. ${ }^{10}$ Figure C3 in the Appendix provides an example of the market interface.

In all treatment conditions, after observing the additional feedback (and after participating in the market in the Market condition) and before proceeding to the next round, subjects are asked to submit an additional confidence report (posterior beliefs) in the same format as their initial confidence report. The payment scheme for the second confidence report is the same as the first one.

After playing all four rounds we measure risk-aversion, using the method by Gneezy and Potters (1997) — subjects receive an initial 3 CHF balance and decide how much of it to invest in a project that generates 6 times the investment with 25 percent probability and loses the investment with 75 percent probability. We also measure ambiguity attitudes by eliciting the certainty equivalent of a bet that pays 5 CHF if a color of the participant's choice (red or black) is drawn from an urn that consists of 10 red and black balls of unknown composition. To measure ambiguity aversion, we compare this certainty equivalent with the certainty equivalent of a lottery that pays $5 \mathrm{CHF}$ with a probability of 50 percent. Finally, subjects fill out a survey eliciting various demographic characteristics.

To determine payments, we draw one of the four rounds and pay for the relative performance in that round's knapsack problem. Then a different round is randomly selected. One of the two belief estimates in this round is randomly drawn to count for the payment. Finally, in the Market condition, a third and different round is randomly selected to count for the market payment. This procedure limits possibilities for hedging within a round. In addition to these

\footnotetext{
"matched subject" ("matched group") observe to which person (group) this ball corresponds. This means that so the subject and the "matched subject" receive perfectly negative correlated signals about their own relative performance.

${ }^{9}$ In the Market condition, we only measure beliefs before the signal and after the market stage, but not between these two stages. We do so to keep the treatment conditions as similar as possible.

${ }^{10}$ In each round and market, three randomly drawn subjects start with 5 assets and 0 CHF cash, the three other subjects start with -5 assets and $10 \mathrm{CHF}$ cash. In addition, each subject receives a loan of 6 CHF for trading that has to be paid back. We allow short selling. Trading is restricted in that trades are not allowed if they result in a negative cash balance, or if they potentially generate losses of more than the loan received.
} 
payments, subjects receive all their payoffs from the tasks eliciting risk aversion and ambiguity attitudes.

Subjects were informed about the full procedure before the experiment started.

\subsection{Procedures}

Subjects were students from the joint subject pool of the University of Zurich and the Swiss Federal Institute of Technology (ETH). The experiment was programmed in z-Tree (Fischbacher, 2007) and participants were recruited with hroot (Bock et al., 2014).

At the beginning of a session, subjects received detailed instructions on knapsack problems, on the procedures for performing the task, on how payments would be determined, and, in the Market condition, on the market. All instructions were delivered both on paper and with pre-recorded audio files. Instructions and materials are available in Appendix D. ${ }^{11}$ To ensure that subjects understood the instructions, they answered comprehension questions before the start of the experiment. Subjects also saw a trial knapsack problem to familiarize them with the structure of the problem and the solution interface. To familiarize subjects with the market interface in the Market condition, they participated in a trial market. In this trial market, subject traded assets whose payoffs depended on a virtual coin flip. We did not incentivize this trial period.

We collected data from a total of 324 subjects, 48 subjects in the Individual condition, 144 subjects in the Collective condition, and 132 subjects in the Market condition. The sessions lasted about 75 minutes in the Individual and Collective conditions and 120 minutes in the Market condition. Average earnings were CHF 44.46 ( $\mathrm{sd}=\mathrm{CHF} 17.71)$, or around US $\$ 45$.

\subsection{Econometric specification}

To investigate biases in belief updating, we compare the observed updating to the Bayesian benchmark. Previous studies on processing of ego-relevant information focus on two deviations from Bayesian updating: asymmetric updating and conservatism. Asymmetric updating means that people react more strongly to positive than negative signals, a mechanism facilitating the preservation of positive self-image. Conservatism means that people react less strongly to the signals than predicted by Bayes' rule. We follow Möbius et al. (2017) and the subsequent

\footnotetext{
${ }^{11}$ We follow the use of voice recordings to deliver instructions, as in Bartling, Engl and Weber (2015). This, combined with standardized instructions and computerized interfaces, ensures highly replicable environments across sessions.
} 
literature by estimating the following regression model, a linearized version of Bayes' rule (see also Grether, 1980; Augenblick and Rabin, 2021):

$$
\operatorname{logit}\left(\text { posterior }_{i}\right)=\delta_{t} \operatorname{logit}\left(\text { prior }_{i}\right)+\beta_{L, t} \lambda_{L} \mathbf{1}\left(s_{i}=\text { neg. }\right)+\beta_{H, t} \lambda_{H} \mathbf{1}\left(s_{i}=\text { pos. }\right)+\varepsilon_{i}
$$

where $t$ denotes the treatment condition (Individual, Collective or Market), $\mathbf{1}\left(s_{i}=\right.$ pos.) is an indicator of a positive signal, and $\lambda_{H}=-\lambda_{L}=\ln (2)$ is the $\log$ likelihood ratio of a positive signal. Note that $\delta_{t}$ measures the weight placed on prior beliefs, and $\beta_{L, t}$ and $\beta_{H, t}$ measures how strongly subjects react to negative and positive signals, respectively. If subjects update according to Bayes' rule, then $\delta_{t}=\beta_{L, t}=\beta_{H, t}=1$. Asymmetric updating favoring a positive self-image is defined as $\beta_{L, t}<\beta_{H, t}$ and conservatism as $\beta_{L, t}, \beta_{H, t}<1$. Finally, $\delta_{t}<1$ can be interpreted as base-rate neglect and $\delta_{t}>1$ as confirmation bias (Augenblick and Rabin, 2021). We exclude observations where subjects update in the wrong direction. We discuss such mistakes in belief updating in the next section.

\section{Results}

We first briefly assess the degree to which subjects' updating process represents an at least partially sensible response to information. We then discuss overconfidence in priors and study biases in belief updating for individual outcomes, replicating earlier work. Next, we address the main questions of this paper: Do people update beliefs about collective outcomes in a selfserving way? And, if so, do such biases in beliefs about collective outcomes differ from biases for individual outcomes? In the last section, we discuss the results of the Market condition. ${ }^{12}$

\subsection{Updating mistakes}

In this section, we discuss mistakes in belief updating, in particular updates in the wrong direction. We also investigate whether participants change their beliefs in response to the

\footnotetext{
${ }^{12}$ Since actual performance on the knapsack problems is not our focus, we do not analyze this measure in detail. In the Individual condition, subjects successfully find the optimal solution to the knapsack problem in $29.2 \%$ of all cases. The success rate is lower than in Murawski and Bossaerts (2016). This difference is likely due to subjects having less time to solve the knapsack problem in our experiment (up to 90 s time difference). Groups' success rates are $73.7 \%$ in the Collective condition, and $78.4 \%$ in the Market condition. In the Collective and Market conditions, each subject sent on average 1.1 messages per round while working on the task.
} 
(informative) signal. ${ }^{13}$ Updating mistakes are indicators of loss of experimental control that can be due, for example, to unclear instructions.

In the Collective condition, $17.9 \%$ of subjects update at least once in the wrong direction and a total of $6.7 \%$ of the updating decisions go in the wrong direction. Moreover, subjects do not update their beliefs in response to the signal in $25.6 \%$ of all updating decisions and $4.2 \%$ of subjects do not update their beliefs in any of the four rounds. We find similar frequencies in the Individual condition (see Table A1 in the Appendix). Previous studies (e.g., Möbius et al, 2017) find more frequent updating mistakes, indicating the high data quality of our study.

Subjects in the Market condition receive multiple signals: the signal from the urn and signals from the market. It is therefore less clear what is a parsimonious definition of incorrect updating. ${ }^{14}$ We consider an update as a mistake if the subject increases her belief in response to a negative signal from both the urn and the market, or if the subject decreases her belief in response to a positive signal from both the urn and the market. ${ }^{15}$ Mistakes are somewhat more common in the Market condition than in the other treatment conditions: $23.5 \%$ of subjects update at least once in the wrong direction and $8.3 \%$ of subjects do not update their beliefs in any of the four rounds (see Table A1 in the Appendix). This is likely due to the updating decision being more complicated in the Market condition.

\subsection{Priors: Confidence about individual and collective outcomes}

Figure 1 shows the cumulative distribution of prior beliefs about winning the competition for all three treatment conditions. On average, the prior belief is $57.9 \%$ in the Collective condition, $56.6 \%$ in the Individual condition and $59.3 \%$ in the Market condition. ${ }^{16}$ In each condition, average beliefs are statistically higher than $50 \%$ (p-value $<0.01)$, indicating moderate degrees of overconfidence. ${ }^{17}$ Biases do not differ between treatment conditions: Subjects exhibit similar

\footnotetext{
${ }^{13}$ On average, subjects react to the signal. Table 2 shows that the posterior beliefs are substantially and significantly lower for subjects who receive a positive signal compared to subjects who receive a negative signal.

${ }^{14}$ Suppose, for example, that a subject first receives a negative signal, but the market price reflects more confidence than this subject's prior. As the subject receives a negative signal from the urn, and a positive signal from the market, the subject might increase or decrease her belief.

${ }^{15}$ To define the market signal, we calculate the price of the last 10 trades, divided by 2 . This is a measure of the optimism manifested in the market price. If this normalized price is higher than a subject's prior, it is considered a positive market signal for the subject; if the price is lower than the prior, it is considered a negative market signal for the subject.

${ }^{16}$ Priors do not differ significantly between rounds nor between knapsack problems. Prior beliefs are predictive of actual relative performance: a one percentage point higher belief translates into a $0.15 \%$ percentage point higher probability to actually be better (p-value $=0.027$ ).

${ }^{17}$ In the following analysis, standard errors are clustered on the matched-individual level (the two matched individuals form a cluster) in the Individual condition and on the matched-group level (the two matched groups form a cluster) in the Collective and Market conditions.
} 
levels of confidence about collective and individual outcomes. We conclude that, in the aggregate, overconfidence is as prevalent for collective outcomes as for individual outcomes.

\section{Figure 1: Distributions of prior beliefs by condition}

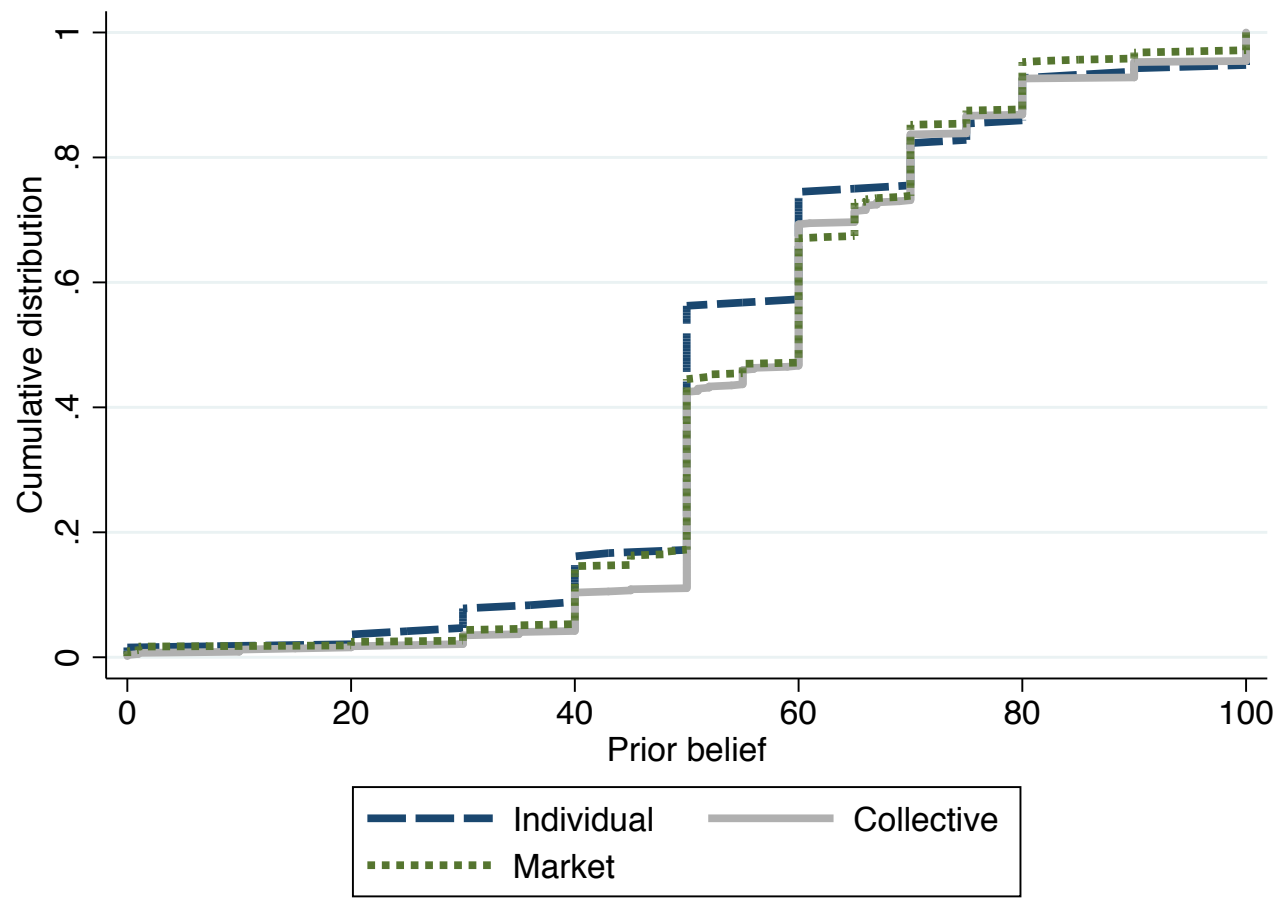

\subsection{Updating beliefs about individual outcomes}

Before we study how participants update beliefs about collective outcomes, we investigate whether our results replicate earlier work on self-serving biases in updating beliefs about individual outcomes. Figure 2 shows the mean absolute belief update conditional on the prior and the signal for the Individual condition, using a similar approach to Möbius et al. (2017). The figure compares subjects who received a positive signal and had a prior belief $\mu$ with subjects who received a negative signal and had a prior belief of $1-\mu$. If participants are Bayesians, the absolute magnitude of the belief update should be the same for both groups. If people update asymmetrically, however, the belief update should be larger for positive signals than for negative signals. For intermediate priors, we find that subjects update asymmetrically. For the very extreme prior category $0-9 \%$, we find that subjects react more strongly to negative than to positive signals. This difference, however, is based on only six observations, and is not 
statistically significantly different from zero. If we compare the mean absolute belief revision with the Bayesian benchmark (red crosses), we see that subjects with low priors overreact to the signal, in particular if they receive a good signal. Subjects with intermediate priors tend to be conservative, particularly when they receive a negative signal.

Figure 2: Asymmetric updating in the Individual condition

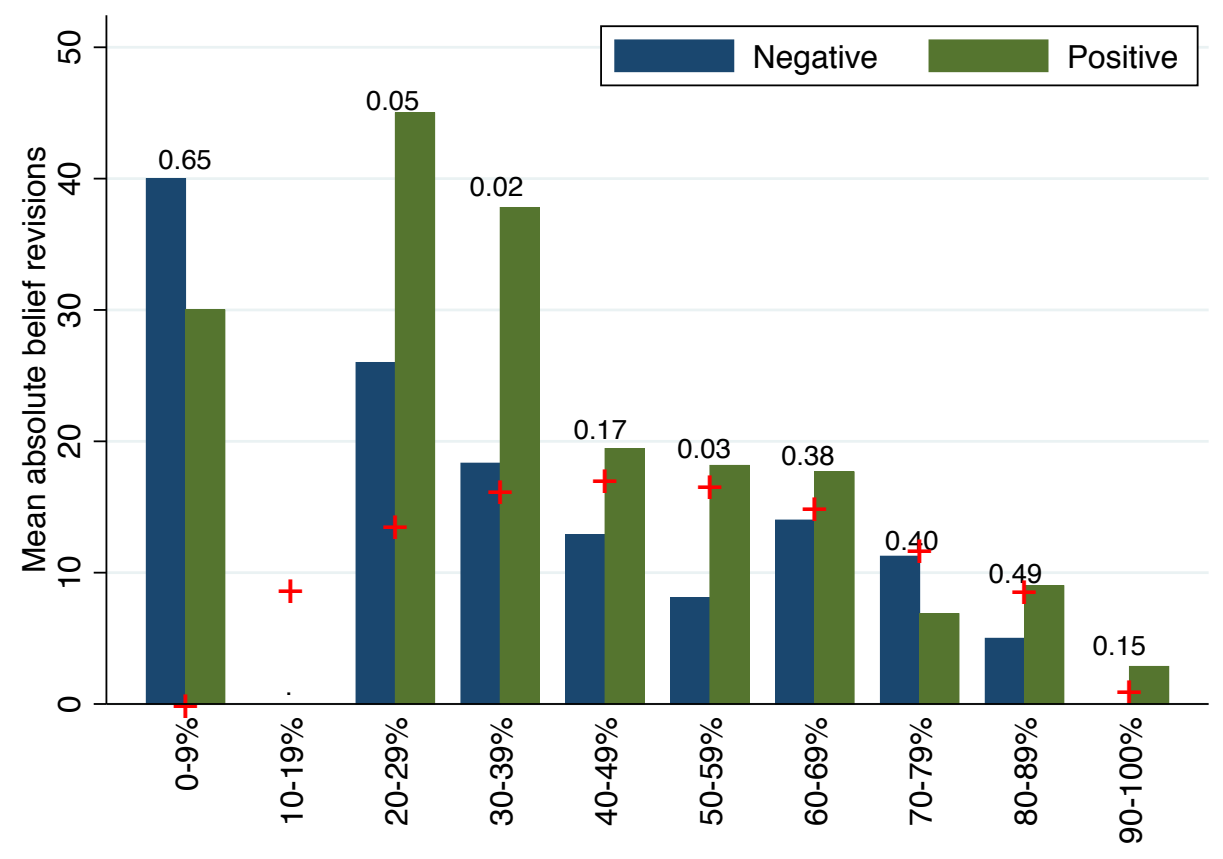

Mean absolute belief revisions by decile of prior belief in being of type equal to the signal received (following Möbius et al., 2017). + indicates the rational benchmark of Bayesian updating. Observations where people updated in the wrong direction are excluded. The numbers on top of the bars indicate p-values, testing whether the update in response to the negative and positive signals is equal.

The first column of Table 1 reports the estimated coefficients from model (1) for the Individual condition. ${ }^{18} \mathrm{We}$ find evidence for base-rate neglect $\left(\hat{\delta}_{\text {Individual }}<1\right.$, p-value $\left.<0.01\right)$. Moreover, we find that subjects react conservatively in response to negative signals $\left(\hat{\beta}_{L, \text { Individual }}<1, \mathrm{p}\right.$-value $\left.=0.014\right)$. For positive signals, however, behavior corresponds to the Bayesian benchmark ( $\hat{\beta}_{H, \text { Individual }}$ is close to 1$)$. Hence, subjects put more weight on positive signals than negative signals; that is, they update asymmetrically ( $\mathrm{p}$-value $=0.003$ ). Given that the non-parametric analysis revealed different updating patterns for extreme priors, we also report

\footnotetext{
${ }^{18}$ Note that the logit does not exist for the priors at the boundary ( 0 and 100$)$. We follow the previous literature by excluding these observations.
} 
estimated coefficients when restricting the sample to observations with priors in $[20,80]$. Estimates are similar (see Table 1, column 4). Table A2 in the Appendix demonstrates that the results are robust to other sample restrictions.

Comparing our estimates to previous studies, we find similar degrees of conservatism as Schwardmann and Van der Weele (2020) and Coutts (2019). However, unlike some earlier replications of Möbius et al. (2017) (see Buser et al., 2018; Schwardmann and Van der Weele, 2020; Coutts, 2019) we find robust evidence of asymmetric updating. ${ }^{19}$

Table 1: Updating behavior in Individual and Collective conditions

\begin{tabular}{llll|lll}
\hline Subsample: & \multicolumn{3}{c|}{ Priors in (0,100) } & \multicolumn{3}{c}{ Priors in [20,80] } \\
\hline & Individual & Collective & Difference & Individual & Collective & Difference \\
\hline$\widehat{\boldsymbol{\delta}}_{\boldsymbol{t}}$ & $0.627^{* * *}$ & $0.710^{* * *}$ & -0.082 & $0.542^{* * *}$ & $0.642^{* * *}$ & -0.100 \\
$\widehat{\boldsymbol{\beta}}_{\boldsymbol{L}, \boldsymbol{t}}$ & $(0.094)$ & $(0.057)$ & $(0.108)$ & $(0.120)$ & $(0.075)$ & $(0.140)$ \\
$\widehat{\boldsymbol{\beta}}_{\boldsymbol{H}, \boldsymbol{t}}$ & $0.671^{* *}$ & $0.678^{* * *}$ & -0.006 & $0.642^{* * *}$ & $0.597^{* * *}$ & 0.045 \\
& $(0.123)$ & $(0.054)$ & $(0.133)$ & $(0.112)$ & $(0.041)$ & $(0.118)$ \\
\hline $\mathbf{N}$ & 1.133 & $0.834^{* *}$ & $0.299^{* *}$ & 1.090 & $0.881^{*}$ & $0.209^{*}$ \\
$\mathbf{p}\left(\widehat{\boldsymbol{\delta}}_{\boldsymbol{t}}==\mathbf{1}\right)$ & $(0.111)$ & $(0.073)$ & $(0.131)$ & $(0.102)$ & $(0.060)$ & $(0.117)$ \\
$\mathbf{p}\left(\widehat{\boldsymbol{\beta}}_{\boldsymbol{L}, \boldsymbol{t}}=\mathbf{1}\right)$ & 160 & 475 & & 159 & 459 & \\
$\mathbf{p}\left(\widehat{\boldsymbol{\beta}}_{\boldsymbol{H}, \boldsymbol{t}}==\mathbf{1}\right)$ & 0.001 & 0.000 & & 0.001 & 0.001 & \\
$\mathbf{p}\left(\widehat{\boldsymbol{\beta}}_{\boldsymbol{L}, \boldsymbol{t}}==\widehat{\boldsymbol{\beta}}_{\boldsymbol{H}, \boldsymbol{t}}\right)$ & 0.014 & 0.000 & & 0.004 & 0.000 & \\
\hline
\end{tabular}

Note: Estimated coefficients of model (1). Priors in (0,100): Observations where people updated in the wrong direction or with a prior $=0$ or $=100$ are excluded. Priors in [20,80]: Observations where people updated in the wrong direction or with a prior $<20$ or $>80$ are excluded. Standard errors clustered at matched-individual/group level; Standard errors in parentheses; Coefficient is significantly different from 1 (Bayesian benchmark) at ${ }^{*}-p<0.1 ; * *-p<0.05 ; * * *-p<0.01$. $p(H)$ gives the $p$-value for testing hypothesis $H$.

\subsection{Updating beliefs about collective outcomes}

Do these biases in the formation of beliefs about individual outcomes extend to beliefs about collective outcomes? In the following, we replicate the above analysis for the Collective condition. Figure 3 illustrates the mean absolute belief revision for the Collective condition, in a manner similar to Figure 2. We find a similar pattern as in the Individual condition: subjects with intermediate priors exhibit asymmetric updating and conservatism.

\footnotetext{
${ }^{19}$ Our study differs in some aspects from the previous studies: subjects update their prior only once in each round, and we use a different task (the knapsack task).
} 


\section{Figure 3: Asymmetric updating in the Collective condition}

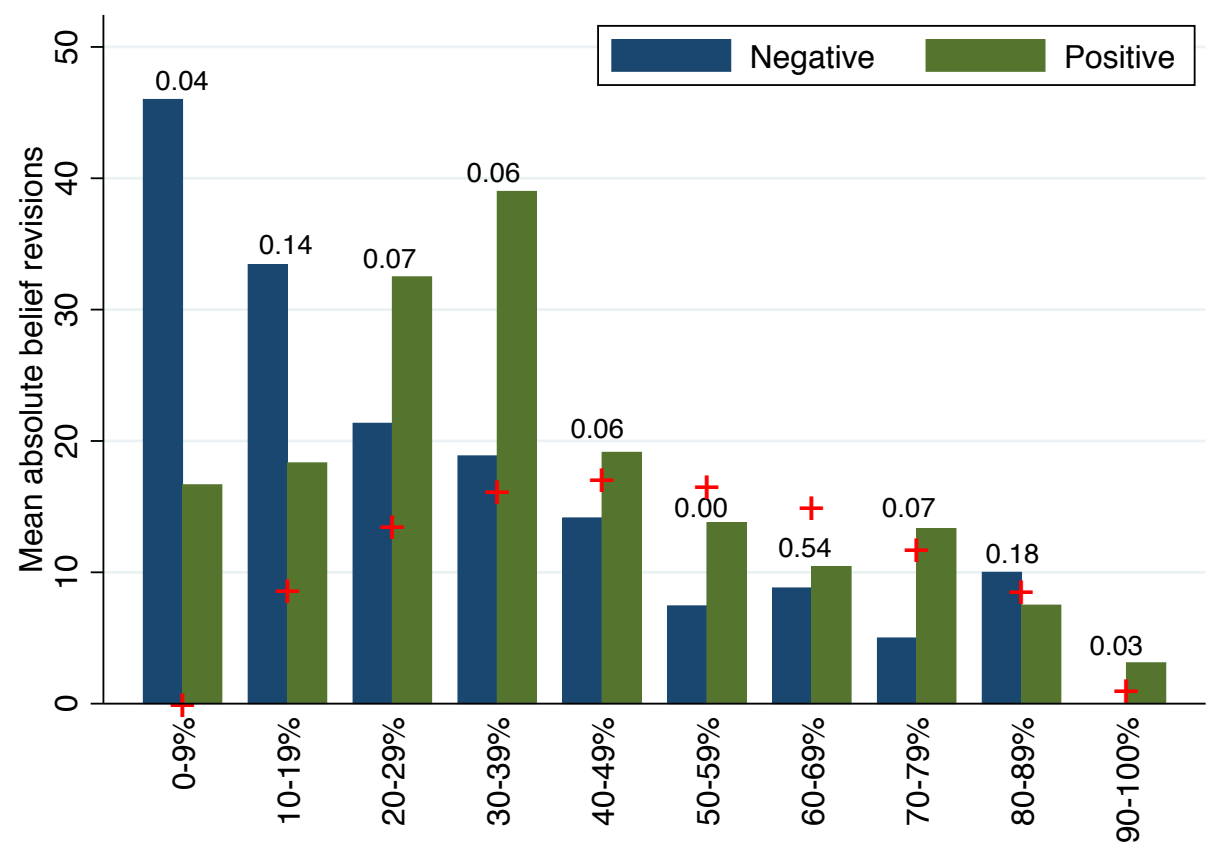

Mean absolute belief revisions by decile of prior belief in being of type equal to the signal received (following Möbius et al., 2017). + indicates the rational benchmark of Bayesian updating. Observations where people updated in the wrong direction are excluded. The number on top of the bars indicate p-values.

Table 1, columns 2 and 5, give the parameter estimates of model (1) for the Collective condition. As in the Individual condition, we find base-rate neglect, conservatism and asymmetry in belief updating. However, the difference between $\hat{\beta}_{L, \text { Group }}$ and $\hat{\beta}_{H, \text { Group }}$ is only statistically significant if we exclude observations with extreme priors (see Table A2 in the Appendix for different sample restrictions).

Columns 3 and 6 compare estimates between the Collective and the Individual conditions. There is some evidence for treatment differences in updating: subjects put slightly less weight on positive signals in the Collective condition compared to the Individual condition ( $p$-value $=0.029$, entire sample). However, we cannot reject the joint hypothesis that all three coefficients are the same across the treatment conditions ( $p$-value $=0.159$ ).

Instead of comparing individual belief updating, we can also compare average posteriors between treatment conditions. We do this in Table 2. In line with our analysis of individual belief updating, we do not find substantial differences in aggregate beliefs between the Individual and Collective conditions. There is weak evidence that, after receiving a negative signal, subjects in 
the Collective condition are more confident than subjects in the Individual condition (pvalue $=0.09$ ). However, we can not reject the joint hypothesis that both differences are zero (pvalue $=0.12$ ). We therefore conclude that biased information processing exists for beliefs about collective outcomes in a manner similar to how they occur for individual outcomes.

Table 2: Posterior beliefs

\begin{tabular}{llllll}
\hline & $\begin{array}{l}\text { Individual } \\
(\mathbf{I})\end{array}$ & $\begin{array}{l}\text { Collective } \\
(\mathbf{C})\end{array}$ & Market (M) & $\begin{array}{l}\text { Difference } \\
\text { I and C }\end{array}$ & $\begin{array}{l}\text { Difference } \\
\text { C and M }\end{array}$ \\
\hline Mean & $57.5^{* * *}$ & $57.9^{* * *}$ & $55.1^{* * *}$ & 0.44 & $-2.80^{*}$ \\
& $(1.62)$ & $(1.22)$ & $(0.99)$ & $(1.99)$ & $(1.52)$ \\
\hline Negative signal & $42.5^{* * *}$ & $46.5^{* * *}$ & $47.0^{* * *}$ & $4.0^{*}$ & 0.44 \\
& $(1.86)$ & $(1.48)$ & $(1.41)$ & $(2.34)$ & $(1.97)$ \\
Positive signal & $72.4^{* * *}$ & $69.5^{* * *}$ & $63.2^{* * *}$ & 2.9 & $-6.29 * * *$ \\
& $(2.43)$ & $(1.62)$ & $(1.26)$ & $(2.88)$ & $(1.99)$ \\
Difference & $29.9^{* * *}$ & $23.0^{* * *}$ & $16.2^{* * *}$ & & \\
& $(2.89)$ & $(2.00)$ & $(1.80)$ & & \\
\hline
\end{tabular}

Note: Standard errors clustered at matched-individual/group level; Standard errors in parentheses;

$*-p<0.1 ; * *-p<0.05 ; * * *-p<0.01$.

\subsection{Market condition}

In this section we analyze behavior in the Market condition. ${ }^{20}$ The first row of Table 3 shows the trading volume. Subjects interacted frequently in the markets; on average, a subject traded about 4 assets per market round. Trading reflects subjects' beliefs about their group's performance: at the end of the market round, more optimistic subjects owned more assets than less optimistic subjects (see Table A3 in the Appendix). The trading volume is independent of the group's signal.

The second row of Table 3 gives the average market prices conditional on the signal. ${ }^{21}$ The price is normalized such that a risk-neutral trader would buy the asset if she believed that the probability of winning the competition was higher than the normalized price, and she would sell the asset if she believed that it was lower than the price. Market prices incorporate signals: the average market price is substantially higher, by 16.5, if participants receive a positive signal.

\footnotetext{
${ }^{20}$ Behavior in the trial market round suggests that subjects understand how the market works. In the trial market round, subjects trade a risky asset (not incentivized), which is not connected to subjects' self-images. Prices in this trial market are close to CHF 1.00 , the equilibrium prediction: the average price is CHF 1.10 and the median price is CHF 1.00 .

${ }^{21}$ Figure A1 in the Appendix gives the cumulative distributions for market prices. Figure A2 shows average market prices for the four rounds separately; prices do not substantially differ between rounds. Figure A3 in the Appendix gives the price development over trading rounds.
} 
The third row of Table 3 shows the objective expected value of the assets conditional on the signal. ${ }^{22}$ Average prices are substantially higher than the expected value, in particular for markets that received a negative signal. Prices express even more optimism than the posterior beliefs documented in the Collective condition (69.5 for positive signals and 46.5 for negative signals, see Table 2), an estimate for what the beliefs in the Market condition might have been before subjects start trading. These high prices are consistent with evidence that people are reluctant to bet against the occurrence of desired outcomes (Seybert and Bloomfield, 2009; Morewedge, Tang and Larrick, 2018).

Table 3: Trading volume and asset prices

\begin{tabular}{clll}
\hline & $\begin{array}{l}\text { Group } \\
\text { signal } \\
\text { positive }\end{array}$ & $\begin{array}{l}\text { Group } \\
\text { signal } \\
\text { negative }\end{array}$ & Difference \\
\hline Number of assets traded & 3.83 & 4.03 & -0.2 \\
(per participant) & $(0.25)$ & $(0.59)$ & $(0.51)$ \\
\hline Asset price, normalized & 80.4 & 63.9 & $16.5 * * *$ \\
Expected value of asset & $(2.56)$ & $(4.02)$ & $(3.28)$ \\
\hline
\end{tabular}

Note: Price asset normalized is the average market price for the last 10 trades, divided by 2 (normalized). Expected value of asset is the normalized expected value of the asset $=2 / 3 * 200 / 2$ resp. $1 / 3 * 200 / 2$.

Are the individual biases that we observe in the Collective condition mitigated by the collective judgment produced in markets? Or, does the collective over-optimism expressed in market prices bias participants' beliefs even more $?^{23}$ To study the impact of the market on subjects' beliefs, we estimate the parameters of model (1) for the Market condition; we regress subjects' posteriors (that is, their beliefs after they observed signals and then interacted in the market) on their priors and the signal from the urn. ${ }^{24}$ We then compare the resulting coefficients to the Collective condition. ${ }^{25}$ Table 4 gives the estimates. We also report estimates for the sample restricted to observations with a prior in $[20,80]$.

\footnotetext{
${ }^{22}$ The average empirical value of the assets is almost the same as the expected value.

${ }^{23}$ After controlling for the groups' signals, the market price is not predictive of winning the competition ( $p$-value $\left.=0.982\right)$. This suggests that, from a normative point of view, subjects should not react to the market prices.

${ }^{24}$ We therefore do not explicitly study how subjects incorporate market signals, such as prices, in their updating behavior. Instead, we estimate a similar model as for the Collective condition. This approach allows us to study whether the market interaction affects belief updating. In Appendix B, we incorporate market signals into model (1) and provide the corresponding estimates.

${ }^{25}$ Figure A4 in the Appendix replicates Figure 2, that is, the non-parametric analysis, for the Market condition. We find a similar pattern as in the Collective condition.
} 
Table 4: Updating behavior in Market condition

\begin{tabular}{llll|lll}
\hline Subsample: & \multicolumn{3}{c|}{ Priors in (0,100) } & \multicolumn{3}{c}{ Priors in [20,80] } \\
\hline & Collective & Market & Difference & Collective & Market & Difference \\
\hline$\widehat{\boldsymbol{\delta}}_{\boldsymbol{t}}$ & $0.710^{* * *}$ & $0.643^{* *}$ & 0.067 & $0.642^{* * *}$ & $0.455^{* * *}$ & $0.187^{* *}$ \\
$\widehat{\boldsymbol{\beta}}_{\boldsymbol{L}, \boldsymbol{t}}$ & $(0.057)$ & $(0.137)$ & $(0.145)$ & $(0.075)$ & $(0.050)$ & $(0.089)$ \\
$\widehat{\boldsymbol{\beta}}_{\boldsymbol{H}, \boldsymbol{t}}$ & $0.678^{* * *}$ & $0.411^{* * *}$ & $0.267^{*}$ & $0.597^{* * *}$ & $0.317^{* * *}$ & $0.280^{* * *}$ \\
\hline $\mathbf{N}$ & $(0.054)$ & $(0.130)$ & $(0.137)$ & $(0.041)$ & $(0.075)$ & $(0.083)$ \\
$\mathbf{p}$-value $\widehat{\boldsymbol{\delta}}_{\boldsymbol{t}}==\mathbf{1}$ & $0.834^{* *}$ & $0.679^{* * *}$ & 0.155 & $0.881^{*}$ & $0.813^{* * *}$ & 0.068 \\
p-value $\widehat{\boldsymbol{\beta}}_{\boldsymbol{L}, \boldsymbol{t}}=\mathbf{1}$ & $(0.073)$ & $(0.095)$ & $(0.117)$ & $(0.060)$ & $(0.050)$ & $(0.076)$ \\
p-value $\widehat{\boldsymbol{\beta}}_{\boldsymbol{H}, \boldsymbol{t}}==\mathbf{1}$ & 475 & 453 & & 459 & 441 & \\
p-value $\widehat{\boldsymbol{\beta}}_{\boldsymbol{L}, \boldsymbol{t}}==\widehat{\boldsymbol{\beta}}_{\boldsymbol{H}, \boldsymbol{t}}$ & 0.000 & 0.026 & & 0.001 & 0.000 & \\
\hline
\end{tabular}

Note: Estimated coefficients of model (1). Priors in (0,100): Observations where people updated in the wrong direction or with a prior $=0$ or $=100$ are excluded. Priors in [20,80]: Observations where people updated in the wrong direction or with a prior $<20$ or $>80$ are excluded. Standard errors clustered at matched-individual/group level; Standard errors in parentheses; Coefficient is significantly different from 1 at $*_{-} p<0.1 ; * *-p<0.05 ; * * *-p<0.01$.

For both the full and the restricted samples, we can reject the joint hypothesis that all three estimates are the same across the Market and Collective conditions ( $\mathrm{p}$-value $=0.013$ and $\mathrm{p}$ value $=0.002$, respectively). For subjects with intermediate priors, we find a larger degree of base-rate neglect in the Market condition than in the Collective condition $\left(\hat{\delta}_{\text {Market }}<\hat{\delta}_{\text {Group }}\right)$. A potential explanation is that subjects update their beliefs not only in response to the signal from the urn but also in response to signals from the markets. These additional updates reduce the weight of the initial prior (see Appendix B).

Compared with the Collective condition, subjects in the Market condition react less to negative signals. For intermediate priors, the difference in $\hat{\beta}_{L, t}$ is statistically significant at the 1\%-level. This finding is robust to different sample restrictions (see Table A4 in the Appendix). After receiving a bad signal, the optimism reflected in market prices seems to help subjects to partly restore their confidence. ${ }^{26} \mathrm{We}$ do not find a treatment difference for positive signals. This potentially reflects the fact that the assets exhibit less overpricing after receiving a positive signal.

Instead of comparing individual belief updating, we can also compare average posteriors between treatment conditions. We do this in Table 2. The average posterior of subjects who

\footnotetext{
${ }^{26}$ We find some evidence that subjects incorporated market signals in their beliefs (see Appendix B for details).
} 
received a positive signal is 6.3 percentage points lower than the posterior in the Collective condition ( $\mathrm{p}$-value $=0.005)$. There is no treatment difference for subjects who received a negative signal. At first glance, this seems to be in contradiction with the finding that individual updating differs only in response to negative signals $\left(\beta_{L, t}\right)$, not in response to positive signals $\left(\beta_{H, t}\right)$. However, these two findings can be explained by the fact that we observe a second treatment effect, a stronger degree of base-rate neglect in the Market condition.

We conclude that the market does not mitigate biases in belief formation regarding collective outcomes. If anything, we find that biases are exacerbated: compared to the Collective condition, subjects underreact even more to negative signals in the Market condition.

\section{Conclusion}

We explore whether over-optimism and self-serving biases in information processing exist for collective outcomes in a manner similar to how they occur for individual outcomes. We first show that subjects exhibit such biases for beliefs about individual outcomes: subjects are overconfident and update their beliefs asymmetrically in response to new information. That is, they put more weight on good news than on bad news. This replicates patterns found in manybut not all-previous studies that investigate this question.

We then investigate biases in beliefs about collective outcomes. As with beliefs about individual outcomes, subjects also exhibit self-serving beliefs about collective outcomes, and magnitudes are remarkably similar to those for biases about individual outcomes. Thus, our first main novel contribution is to document that the tendency to overweight positive information more than negative information, i.e., asymmetric updating, also extends to the formation of beliefs about collective outcomes. Given the importance of beliefs about such outcomes - from macroeconomic performance to firm profitability - for a wide variety of economic behaviors, this observation is important.

We also investigate how such belief formation is influenced by the presence of an information aggregation institution, specifically, a market. Collective self-delusion potentially plays an important role for market outcomes. However, it has been argued that markets can mitigate individual biases. We find that the market institution, if anything, exacerbates biases. We also observe that market prices depart substantially from fundamentals, in manner consistent with positive self-delusion. Thus, our findings suggest that, rather than reducing the tendency to 
engage in self-serving information processing, aggregating beliefs through an institution such as a market may have the opposite effect. This is consistent with the observation that many instances of such collective self-delusion occur in market contexts, as in speculative bubbles. 


\section{Literature}

Akerlof, G. A., and Dickens, W. T. (1982) "The Economic Consequences of Cognitive Dissonance," American Economic Review, 72(3): 307-319.

Anand, V., Ashforth, B. E. and Joshi, M. (2005) "Business as Usual: The Acceptance and Perpetuation of Corruption in Organizations," Academy of Management Executive, 19(4): 9-23.

Andre, P., Pizzinelli, C., Roth, C. and Wohlfart, J. (2019) "Subjective Models of the Macroeconomy: Evidence from Experts and a Representative Sample," working paper.

Armona, L., Fuster, A. and Zafar, B. (2019) "Home Price Expectations and Behaviour: Evidence from a Randomized Information Experiment," Review of Economic Studies, 86(4): 1371-1410.

Augenblick, N. and Rabin, M. (2021) "Belief Movement, Uncertainty Reduction, and Rational Updating," Quarterly Journal of Economics, forthcoming.

Baillon, A., Cabantous, L. and Wakker, P. P. (2012) "Aggregating imprecise or conflicting beliefs: an experimental investigation using modern ambiguity theories," Journal of Risk and Uncertainty, 44: 115-147.

Barron, K. (2021) "Belief Updating: Does the 'Good-news, Bad-news' Asymmetry Extend to Purely Financial Domains?,” Experimental Economics, forthcoming.

Bartling, B., Engl, F. and Weber, R. A. (2015) "Game form misconceptions are not necessary for a willingness-to-pay vs. willingness-to-accept gap," Journal of the Economic Science Association, 1(1): 72-85.

Bénabou, R. (2013) "Groupthink: Collective Delusions in Organizations and Markets," Review of Economic Studies, 80: 429-462.

Bénabou, R., and Tirole, J. (2006) "Incentives and Prosocial Behavior," American Economic Review, 96(5): 1652-1678.

Bénabou, R., and Tirole, J. (2011). "Identity, Morals, and Taboos: Beliefs as Assets," Quarterly Journal of Economics, 126: 805-855.

Bénabou, R., and Tirole, J. (2016) "Mindful Economics: The Production, Consumption, and Value of Beliefs," Journal of Economic Perspectives, 30(3): 141-164.

Bock, O., Baetge, I., and Nicklisch, A. (2014) "hroot: Hamburg registration and organization online tool," European Economic Review, 71: 117-120. 
Brookins, P., Lucas, A., Ryvkin, D. (2014) "Reducing within-group overconfidence through group identity and between-group confidence judgments," Journal of Economic Psychology, 44, 1-12.

Brunnermeier, M. K., and Parker, J. A. (2005) "Optimal Expectations," American Economic Review 95(4): 1092-1118.

Buser, T., Niederle, M. and Oosterbeek, H. (2014) "Gender, Competitiveness, and Career Choices," Quarterly Journal of Economics, 129(3): 1409-1447.

Buser, T., Gerhards, L., and Van der Weele, J. J. (2018) "Responsiveness to feedback as a personal trait," Journal of Risk and Uncertainty, 56(2): 165-192.

Cacault, M. P. and Grieder, M. (2019) "How group identification distorts beliefs," Journal of Economic Behavior \& Organization, 164: 63-76.

Camerer, C. F. (1987) "Do Biases in Probability Judgment Matter in Markets? Experimental Evidence," American Economic Review, 77(5): 981-997.

Camerer, C., F. Loewenstein, G., and Weber, M. (1989) "The Curse of Knowledge in Economic Settings: An Experimental Analysis," Journal of Political Economy, 97(5): 1232-1254.

Cheng, I., Raina, S., and Xiong, W. (2014) "Wall Street and the Housing Bubble," American Economic Review, 104(9): 2797-2829.

Cotofan, M., Cassar, L., Dur, R., and Meier, S. (2020) "Macroeconomic Conditions When Young Shape Job Preferences for Life," working paper.

Coutts, A. (2019) "Good News and Bad News are Still News: Experimental Evidence on Belief Updating," Experimental Economics, 22(2): 369-395.

Coutts, A., Gerhards, L., and Murad, Z. (2020) "Who to blame? Self-serving attribution bias with multi-dimensional uncertainty," working paper.

Dana, J., Weber, R. A., and Kuang, J. X. (2007) "Exploiting moral wiggle room: experiments demonstrating an illusory preference for fairness," Economic Theory, 33(1): 67-80.

Eil, D. and Rao, J. M. (2011) "The Good News-Bad News Effect: Asymmetric Processing of Objective Information about Yourself," American Economic Journal: Microeconomics, 3(2): 114-138.

Ertac, S. (2011) "Does self-relevance affect information processing? Experimental evidence on the response to performance and non-performance feedback," Journal of Economic Behavior and Organization, 80(3): 532-545. 
Fischbacher, U. (2007) "z-Tree: Zurich toolbox for ready-made economic experiments," Experimental Economics, 10(2): 171-178.

Foote, C. L., Gerardi, K. S., and Willen, P. S. (2012) "Why Did So Many People Make So Many Ex Post Bad Decisions? The Causes of the Foreclosure Crisis," NBER Working Paper.

Forsythe, R., Nelson, F., Neumann, G. R., and Wright, J. (1992) “Anatomy of an Experimental Political Stock Market,” American Economic Review, 82(5): 1142-1161.

Ganguly, A. R., and Tasoff, J. (2017) "Fantasy and Dread: The Demand for Information and the Consumption Utility of the Future." Management Science, 63(12): 3999-4446.

Garrett, N., Sharot, T. (2014) "How Robust Is the Optimistic Update Bias for Estimating SelfRisk and Population Base Rates?," PLoS ONE, 9(6).

Gino, F., Norton, M. I., and Weber, R. A. (2016) "Motivated Bayesians: Feeling Moral While Acting Egoistically,” Journal of Economic Perspectives, 30(3): 189-212.

Gneezy, U., and Potters, J. (1997) “An Experiment on Risk Taking and Evaluation Periods.” Quarterly Journal of Economics, 112(2): 631-645.

Gotthard-Real, A. (2017) "Desirability and Information Processing: An Experimental Study," Economics Letters, 152: 96-99.

Grether, D. M. (1980) "Bayes Rule as a Descriptive Model: The Representativeness Heuristic," Quarterly Journal of Economics, 95(3): 537-557.

Irwin, F. W. (1953) "Stated Expectations as Functions of Probability and Desirability of Outcomes," Journal of Personality, 21(3): 329-335.

Kogan, S., Kwasnica, A. M. and Weber, R. A. (2011) "Coordination in the presences of asset markets," American Economic Review, 101(2): 927-947.

Kuchler, T. and Zafar, B. (2019) "Personal Experiences and Expectations about Aggregate Outcomes," Journal of Finance, 74: 2491-2542.

Ma, Y. (2015) “Bank CEO Optimism and the Financial Crisis,” working paper.

Malmendier, U., and Nagel, S. (2011) "Depression babies: Do macroeconomic experiences affect risk taking?," Quarterly Journal of Economics, 126: 373-416.

Malmendier, U., and Nagel, S. (2016) "Learning from inflation experiences," Quarterly Journal of Economics, 131: 53-87.

Mayraz, G. (2013) “Wishful Thinking,” working paper. 
Möbius, M. M., Niederle, M., Niehaus, P. and Rosenblat, T. S. (2017) "Managing SelfConfidence," working paper.

Morewedge, C. K., Tang, S. and Larrick, R. P. (2018) "Betting Your Favorite to Win: Costly Reluctance to Hedge Desired Outcomes," Management Science, 64(3): 983-1476.

Murawski, C. and Bossaerts, P. (2016) "How Humans Solve Complex Problems: The Case of the Knapsack Problem," Scientific Reports 6.

Niederle, M. and Vesterlund, L. (2007) "Do Women Shy Away from Competition? Do Men Compete Too Much?," Quarterly Journal of Economics, 122(3): 1065-1101.

Oprea, R. and Yuksel, S. (2020) "Social Exchange of Motivated Beliefs," working paper.

Oster, E., Shoulson, I. and Dorsey, E. R. (2013) "Optimal expectations and limited medical testing: Evidence from Huntington disease.” American Economic Review, 103(2): 804830.

Quattrone, G. A., and Tversky, A. (1984) "Causal versus diagnostic contingencies: On selfdeception and on the voter's illusion," Journal of Personality and Social Psychology, 46(2): 237-248.

Rabin, M. (1994) "Cognitive dissonance and social change," Journal of Economic Behavior and Organization, 23: 177-194.

Roth, C. and Wohlfart, J. (2020) "How Do Expectations about the Macroeconomy Affect Personal Expectations and Behavior?," Review of Economics and Statistics, 102(4), 731748.

Saucet, C. and Villeval, M. C. (2019) "Motivated memory in dictator games," Games and Economic Behavior, 117, 250-275.

Seybert, N., and Bloomfield, R. (2009) "Contagion of wishful thinking in markets," Management Science, 55(5): 738-751.

Schwardmann, P. and Van der Weele, J. J. (2020) "Deception and Self-deception," Nature Human Behavior, 3: 1055-1061.

Sharot, T., Korn, C. W. and Dolan, R .J. (2011) "How unrealistic optimism is maintained in the face of reality," Nature Neuroscience, 14(11): 1475-1481.

Shiller, R. J. (2002) "Bubbles, Human Judgment, and Expert Opinion," Financial Analysts Journal, 58(3): 18-26. 
Strong, N. and Xu, X. (2003) "Understanding the Equity Home Bias: Evidence from Survey Data," Review of Economics and Statistics, 85(2): 307-312.

Svenson, O. (1981) "Are we all less risky and more skillful than our fellow drivers?," Acta Psychologica, 47: 143-148.

Tang, S., Huang, H., Bowman, E., Yadav, N., Murawski, C. and Bossaerts, P. (2017) "The Efficient Markets Hypothesis Does Not Hold When Securities Valuation is Computationally Hard," working paper.

Weinstein, N. D. (1980) “Unrealistic optimism about future life events," Journal of Personality and Social Psychology, 39(5): 806-820.

Wiswall, M., and Zafar, B. (2015) "How do college students respond to public information about earnings?," Journal of Human Capital, 9(2): 117-169.

Zimmermann, F. (2020) “The Dynamics of Motivated Beliefs," American Economic Review, 110(2): 337-61. 


\section{Appendix A: Additional results}

Table A1: Updating mistakes

\begin{tabular}{lllll}
\hline & Individual & Collective & Market & $\begin{array}{l}\text { Previous } \\
\text { studies }\end{array}$ \\
\hline percent no update & 28.1 & 25.6 & 32.0 & $36(\mathrm{M}) ; 41(\mathrm{C})$ \\
\hline $\begin{array}{l}\text { percent subjects } \\
\text { never update }\end{array}$ & 2.1 & 4.2 & 8.3 & $16(\mathrm{M})$ \\
\hline $\begin{array}{l}\text { percent updates } \\
\text { wrong direction }\end{array}$ & 3.6 & 6.7 & 8.1 & $\begin{array}{l}10 \quad(\mathrm{M}, \mathrm{B}) ; \quad 4.8 \\
(\mathrm{C})\end{array}$ \\
\hline $\begin{array}{l}\text { percent subjects with at } \\
\text { least one update wrong } \\
\text { direction }\end{array}$ & 12.5 & 17.9 & 23.5 & $27(\mathrm{M})$ \\
\hline
\end{tabular}

Notes: "no update" is defined as the prior being equal to the posterior; "update in the wrong direction" is defined as a negative update in response to a positive signal or a positive update in response to a negative signal for the Individual and Collective condition. For the Market condition, it is defined as a negative update in response to both, a positive signal and a "positive market signal" (average price of the last 10 trades $/ 2>$ prior) or a positive update in response to both, a negative signal and a "negative market signal" (average price of the last 10 trades $/ 2<$ prior). Previous studies gives the percentages from previos studies: (C) refers to Coutts (2019), (B) refers to Buser et al. (2018) and (M) refers to Möbius et al. (2017). 
Table A2: Robustness checks updating

\begin{tabular}{|c|c|c|c|c|c|c|c|}
\hline & $\begin{array}{l}\text { Priors in } \\
(0,100)\end{array}$ & $\begin{array}{l}\text { Priors in } \\
{[10,90]}\end{array}$ & $\begin{array}{l}\text { Priors in } \\
{[20,80]}\end{array}$ & $\begin{array}{l}\text { Priors in } \\
{[30,70]}\end{array}$ & $\begin{array}{l}\text { Priors in } \\
{[40,60]}\end{array}$ & $\begin{array}{l}\text { Möbius } \\
\text { subs. }\end{array}$ & $\begin{array}{l}\begin{array}{l}\text { Möbius } \\
\text { subs. } 2\end{array} \\
\end{array}$ \\
\hline & \multicolumn{7}{|c|}{ Individual condition } \\
\hline \multirow[t]{2}{*}{$\widehat{\delta}_{t}$} & $0.627 * * *$ & $0.627 * * *$ & $0.542 * * *$ & $0.575 * * *$ & 0.871 & $0.650 * * *$ & $0.553 * * *$ \\
\hline & $(0.094)$ & $(0.094)$ & $(0.120)$ & $(0.150)$ & $(0.155)$ & $(0.101)$ & $(0.135)$ \\
\hline \multirow[t]{2}{*}{$\widehat{\boldsymbol{\beta}}_{L, t}$} & $0.671^{* *}$ & $0.671^{* *}$ & $0.642 * * *$ & $0.597 * * *$ & $0.609 * * *$ & $0.703 * *$ & $0.669 * * *$ \\
\hline & $(0.123)$ & $(0.123)$ & $(0.112)$ & $(0.110)$ & $(0.109)$ & $(0.126)$ & $(0.114)$ \\
\hline \multirow[t]{2}{*}{$\widehat{\boldsymbol{\beta}}_{H, t}$} & 1.133 & 1.133 & 1.090 & 1.043 & 0.951 & $1.231^{*}$ & 1.175 \\
\hline & $(0.111)$ & $(0.111)$ & $(0.102)$ & $(0.103)$ & $(0.098)$ & $(0.115)$ & $(0.109)$ \\
\hline $\mathbf{N}$ & 160 & 160 & 159 & 139 & 117 & 142 & 141 \\
\hline p-value $\widehat{\delta}_{t}==1$ & 0.0006 & 0.0006 & 0.0009 & 0.0093 & 0.4117 & 0.0021 & 0.0031 \\
\hline p-value $\widehat{\beta}_{L, t}==1$ & 0.0136 & 0.0136 & 0.0040 & 0.0013 & 0.0015 & 0.0269 & 0.0078 \\
\hline p-value $\widehat{\beta}_{H, t}==1$ & 0.2430 & 0.2430 & 0.3905 & 0.6802 & 0.6202 & 0.0568 & 0.1206 \\
\hline \multirow[t]{2}{*}{ p-value $\widehat{\beta}_{L, t}==\beta_{H, t}$} & 0.0033 & 0.0033 & 0.0048 & 0.0084 & 0.0138 & 0.0024 & 0.0040 \\
\hline & \multicolumn{7}{|c|}{ Collective condition } \\
\hline \multirow[t]{2}{*}{$\widehat{\delta}_{t}$} & $0.710 * * *$ & $0.597 * * *$ & $0.642 * * *$ & $0.598 * * *$ & $0.619^{* * *}$ & $0.706 * * *$ & $0.629 * * *$ \\
\hline & $(0.057)$ & $(0.065)$ & $(0.075)$ & $(0.071)$ & $(0.107)$ & $(0.072)$ & $(0.089)$ \\
\hline \multirow[t]{2}{*}{$\widehat{\boldsymbol{\beta}}_{L, t}$} & $0.678^{* * *}$ & $0.618 * * *$ & $0.597 * * *$ & $0.558 * * *$ & $0.528 * * *$ & $0.735 * * *$ & $0.643 * * *$ \\
\hline & $(0.054)$ & $(0.039)$ & $(0.041)$ & $(0.048)$ & $(0.058)$ & $(0.081)$ & $(0.039)$ \\
\hline \multirow[t]{2}{*}{$\widehat{\boldsymbol{\beta}}_{H, t}$} & $0.834^{* *}$ & $0.900 *$ & $0.881^{*}$ & $0.854 * * *$ & $0.812 * * *$ & 0.901 & 0.960 \\
\hline & $(0.073)$ & $(0.049)$ & $(0.060)$ & $(0.045)$ & $(0.046)$ & $(0.081)$ & $(0.065)$ \\
\hline $\mathbf{N}$ & 475 & 473 & 459 & 414 & 338 & 394 & 380 \\
\hline p-value $\widehat{\delta}_{t}==1$ & 0.0004 & 0.0001 & 0.0006 & 0.0001 & 0.0045 & 0.0018 & 0.0016 \\
\hline p-value $\widehat{\beta}_{L, t}==1$ & 0.0001 & 0.0000 & 0.0000 & 0.0000 & 0.0000 & 0.0072 & 0.0000 \\
\hline p-value $\widehat{\boldsymbol{\beta}}_{H, t}==1$ & 0.0449 & 0.0643 & 0.0715 & 0.0077 & 0.0019 & 0.2481 & 0.5454 \\
\hline \multirow[t]{2}{*}{ p-value $\widehat{\boldsymbol{\beta}}_{L, t}==\boldsymbol{\beta}_{H, t}$} & 0.1536 & 0.0001 & 0.0002 & 0.0000 & 0.0003 & 0.2626 & 0.0007 \\
\hline & \multicolumn{7}{|c|}{ Difference } \\
\hline \multirow[t]{2}{*}{ Difference $\widehat{\delta}_{t}$} & -0.082 & 0.030 & -0.100 & -0.023 & 0.252 & -0.057 & -0.076 \\
\hline & $(0.108)$ & $(0.112)$ & $(0.140)$ & $(0.164)$ & $(0.186)$ & $(0.122)$ & $(0.159)$ \\
\hline \multirow[t]{2}{*}{ Difference $\widehat{\boldsymbol{\beta}}_{L, t}$} & -0.006 & 0.053 & 0.045 & 0.040 & 0.081 & -0.032 & 0.026 \\
\hline & $(0.133)$ & $(0.128)$ & $(0.118)$ & $(0.118)$ & $(0.122)$ & $(0.147)$ & $(0.119)$ \\
\hline \multirow[t]{2}{*}{ Difference $\widehat{\beta}_{H, t}$} & $0.299 * *$ & $0.233 *$ & $0.209^{*}$ & $0.189^{*}$ & 0.139 & $0.331 * *$ & $0.215^{*}$ \\
\hline & $(0.131)$ & $(0.120)$ & $(0.117)$ & $(0.111)$ & $(0.107)$ & $(0.139)$ & $(0.125)$ \\
\hline p-value asym. & 0.083 & 0.228 & 0.284 & 0.355 & 0.679 & 0.086 & 0.274 \\
\hline p-value joint test & 0.159 & 0.220 & 0.373 & 0.410 & 0.452 & 0.100 & 0.401 \\
\hline
\end{tabular}

Note: Estimated coefficients of model (1). Observations where people updated in the wrong direction or with a prior of 0 percent of 100 percent are excluded are excluded. "Priors in [10,90]" means that the sample is restricted to observations with a prior in between 10 percent and 90 percent. Möbius subs. restricts the sample to subjects that never updated in the wrong direction (in the 4 rounds) and to subjects who updated their beliefs at least once (the subsample explored in Möbius et al. (2017)). Möbius subs. 2 restricts Möbius subsample to observations with a prior in [20,80]. "p-value asym." is the p-value from the test on whether there is a difference in asymmetric updating (HO: $\left.\hat{\beta}_{H, \text { Group }}-\hat{\beta}_{H, \text { Group }}=\hat{\beta}_{H, \text { Individual }}-\hat{\beta}_{H, \text { Individual }}\right)$. " $p$-value joint test" is the p-value from a joint test that $\delta_{t}, \beta_{L, t}$ and $\beta_{H, t}$ do not differ between the two treatment conditions (F-test). Standard errors clustered at matched-individual/group level; Standard errors in parentheses; * $-p<0.1$; ** $-p<0.05$; *** $-p<0.01$. 


\section{Table A3: Relationship between beliefs and trading in the market}

\begin{tabular}{ll}
\hline Rank & Average number assets \\
\hline $\mathbf{1}$ (least optimistic) & -0.76 \\
$\mathbf{2}$ & -1.75 \\
$\mathbf{3}$ & -.41 \\
$\mathbf{4}$ & .09 \\
$\mathbf{5}$ & 1.19 \\
$\mathbf{6}$ (most optimistic) & 1.64 \\
\hline
\end{tabular}

\begin{tabular}{ll}
\hline $\begin{array}{l}\text { Dependent } \\
\text { assets }\end{array}$ & Variable: Average number \\
\hline Rank & $0.61 * * *$ \\
& $(0.150)$ \\
Constant & $-2.13^{* * *}$ \\
& $(0.526)$ \\
\hline $\mathbf{N}$ & 528 \\
$\mathbf{R}^{2}$ & .076 \\
\hline
\end{tabular}

Notes: For each round and group, subjects are ranked according to their posterior belief with rank=1 being the least optimistic subject in the group. We then correlate the rank with the number of assets the participant owns at the end of the market period. The total number of assets sum up to 0 by design. Standard errors clustered at matched-group level; Standard errors in parentheses; * $-p<0.1 ; * *-p<0.05 ; * * *-p<0.01$. 
Table A4: Robustness checks updating

\begin{tabular}{|c|c|c|c|c|c|c|c|}
\hline & $\begin{array}{l}\text { Priors in } \\
(0,100)\end{array}$ & $\begin{array}{l}\text { Priors in } \\
{[10,90]}\end{array}$ & $\begin{array}{l}\text { Priors in } \\
{[20,80]}\end{array}$ & $\begin{array}{l}\text { Priors in } \\
{[30,70]}\end{array}$ & $\begin{array}{l}\text { Priors in } \\
{[40,60]}\end{array}$ & $\begin{array}{l}\text { Möbius } \\
\text { subs. }\end{array}$ & $\begin{array}{l}\text { Möbius } \\
\text { subs. } 2\end{array}$ \\
\hline & \multicolumn{7}{|c|}{ Collective condition } \\
\hline \multirow[t]{2}{*}{$\widehat{\delta_{t}}$} & $0.710^{* * *}$ & $0.597 * * *$ & $0.642 * * *$ & $0.598 * * *$ & $0.619^{* * *}$ & $0.706^{* * *}$ & $0.629 * * *$ \\
\hline & $(0.057)$ & $(0.065)$ & $(0.075)$ & $(0.071)$ & $(0.107)$ & $(0.072)$ & $(0.089)$ \\
\hline \multirow[t]{2}{*}{$\widehat{\boldsymbol{\beta}}_{L, t}$} & $0.678 * * *$ & $0.618 * * *$ & $0.597 * * *$ & $0.558 * * *$ & $0.528 * * *$ & $0.735 * * *$ & $0.643 * * *$ \\
\hline & $(0.054)$ & $(0.039)$ & $(0.041)$ & $(0.048)$ & $(0.058)$ & $(0.081)$ & $(0.039)$ \\
\hline \multirow[t]{2}{*}{$\widehat{\boldsymbol{\beta}}_{H, t}$} & $0.834 * *$ & $0.900^{*}$ & $0.881^{*}$ & $0.854 * * *$ & $0.812 * * *$ & 0.901 & 0.960 \\
\hline & $(0.073)$ & $(0.049)$ & $(0.060)$ & $(0.045)$ & $(0.046)$ & $(0.081)$ & $(0.065)$ \\
\hline \multirow[t]{2}{*}{$\mathbf{N}$} & 475 & 473 & 459 & 414 & 338 & 394 & 380 \\
\hline & \multicolumn{7}{|c|}{ Market condition } \\
\hline \multirow[t]{2}{*}{$\widehat{\delta_{t}}$} & $0.643 * *$ & $0.409 * * *$ & $0.455 * * *$ & $0.403 * * *$ & $0.387 * * *$ & $0.514 * * *$ & $0.461 * * *$ \\
\hline & $(0.137)$ & $(0.046)$ & $(0.050)$ & $(0.064)$ & $(0.071)$ & $(0.076)$ & $(0.067)$ \\
\hline \multirow[t]{2}{*}{$\widehat{\boldsymbol{\beta}}_{L, t}$} & $0.411 * * *$ & $0.288 * * *$ & $0.317 * * *$ & $0.304 * * *$ & $0.239 * * *$ & $0.415 * * *$ & $0.406^{* * *}$ \\
\hline & $(0.130)$ & $(0.075)$ & $(0.075)$ & $(0.081)$ & $(0.082)$ & $(0.094)$ & $(0.089)$ \\
\hline \multirow[t]{2}{*}{$\widehat{\boldsymbol{\beta}}_{H, t}$} & $0.679 * * *$ & $0.798 * * *$ & $0.813 * * *$ & $0.787 * * *$ & $0.735 * * *$ & $0.878^{*}$ & 0.889 \\
\hline & $(0.095)$ & $(0.046)$ & $(0.050)$ & $(0.061)$ & $(0.063)$ & $(0.059)$ & $(0.062)$ \\
\hline $\mathbf{N}$ & 453 & 448 & 441 & 394 & 303 & 338 & 334 \\
\hline$p$-value $\delta_{t}==1$ & 0.0261 & 0.0000 & 0.0000 & 0.0000 & 0.0000 & 0.0001 & 0.0000 \\
\hline p-value $\beta_{L, t}==1$ & 0.0011 & 0.0000 & 0.0000 & 0.0000 & 0.0000 & 0.0001 & 0.0001 \\
\hline p-value $\beta_{H, t}==1$ & 0.0069 & 0.0013 & 0.0040 & 0.0061 & 0.0017 & 0.0655 & 0.1013 \\
\hline \multirow[t]{2}{*}{ p-value $\beta_{L, t}==\beta_{H, t}$} & 0.2252 & 0.0002 & 0.0002 & 0.0008 & 0.0005 & 0.0004 & 0.0002 \\
\hline & \multicolumn{7}{|c|}{ Difference } \\
\hline \multirow[t]{2}{*}{ Difference $\widehat{\delta}_{t}$} & 0.067 & $0.188 * *$ & $0.187 * *$ & $0.195 * *$ & $0.232 *$ & $0.193 *$ & 0.168 \\
\hline & $(0.145)$ & $(0.077)$ & $(0.089)$ & $(0.094)$ & $(0.126)$ & $(0.102)$ & $(0.109)$ \\
\hline \multirow[t]{2}{*}{ Difference $\widehat{\boldsymbol{\beta}}_{L, t}$} & $0.267^{*}$ & $0.330 * * *$ & $0.280 * * *$ & $0.253 * *$ & $0.289 * * *$ & $0.319 * *$ & $0.236^{* *}$ \\
\hline & $(0.137)$ & $(0.083)$ & $(0.083)$ & $(0.092)$ & $(0.098)$ & $(0.121)$ & $(0.095)$ \\
\hline \multirow{2}{*}{ Difference $\widehat{\boldsymbol{\beta}}_{H, t}$} & 0.155 & 0.102 & 0.068 & 0.067 & 0.077 & 0.022 & 0.071 \\
\hline & $(0.117)$ & $(0.065)$ & $(0.076)$ & $(0.074)$ & $(0.076)$ & $(0.098)$ & $(0.087)$ \\
\hline p-value asym. & 0.624 & 0.027 & 0.039 & 0.102 & 0.067 & 0.082 & 0.135 \\
\hline p-value joint test & 0.013 & 0.001 & 0.002 & 0.012 & 0.020 & 0.065 & 0.0614 \\
\hline
\end{tabular}

Note: Estimated coefficients of model (1). Observations where people updated in the wrong direction or with a prior of 0 percent of 100 percent are excluded are excluded. "Priors in [10,90]" means that the sample is restricted to observations with a prior in between 10 percent and 90 percent. Möbius subs. restricts the sample to subjects that never updated in the wrong direction (in the 4 rounds) and to subjects who updated their beliefs at least once. Möbius subs. 2 restricts Möbius subsample to observations with a prior in $[20,80]$. " $p$-value asym." is the p-value from the test on whether there is a difference in asymmetric updating (H0: $\left.\hat{\beta}_{H, \text { Group }}-\hat{\beta}_{H, \text { Group }}=\hat{\beta}_{H, \text { Market }}-\hat{\beta}_{H, \text { Market }}\right)$. " $p$-value joint test" is the p-value from a joint test that $\delta_{t}, \beta_{L, t}$ and $\beta_{H, t}$ do not differ between the two treatment conditions (F-test). Standard errors clustered at matched-individual/group level; Standard errors in parentheses; $*-p<0.1 ; * *-p<0.05$; *** $-p<0.01$. 
Figure A1: Distribution market price and trading volume

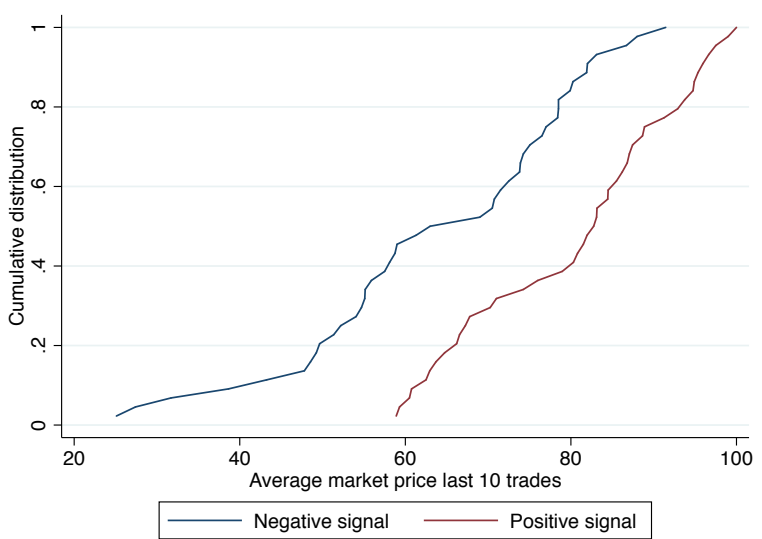

(a) Market price

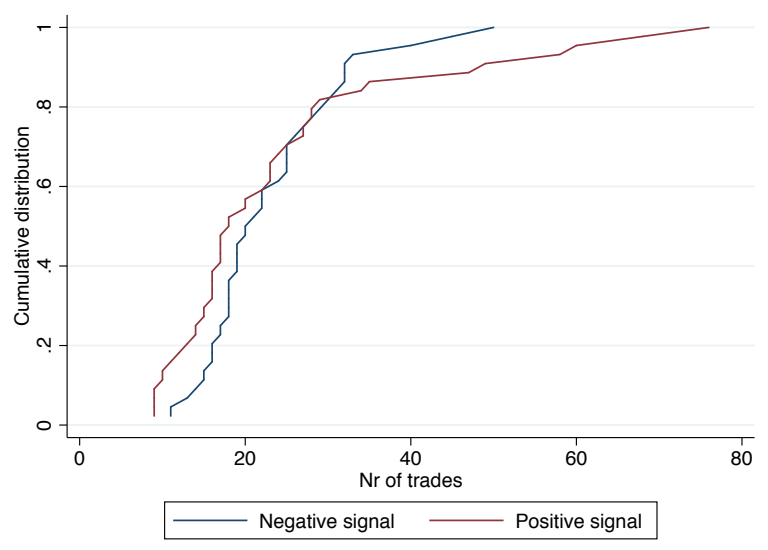

(b) Trading volume

Notes: For each market, we calculate the average price of the last 10 trades and the total number of trades. The figures show the cumulative distributions of these two variables, conditional on the signal.

Figure A2: Market prices over rounds

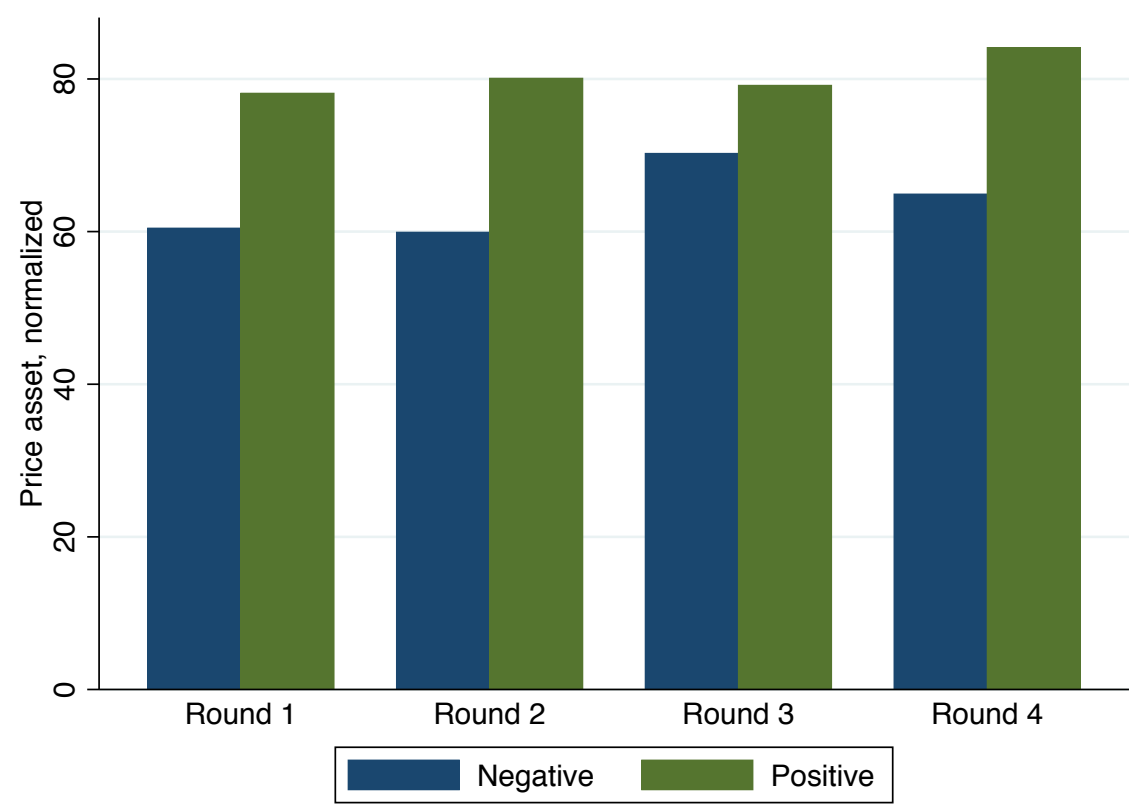

Notes: The figure gives the average asset price conditional on the signal for each of the four market rounds. 


\section{Figure A3: Development market price over time}

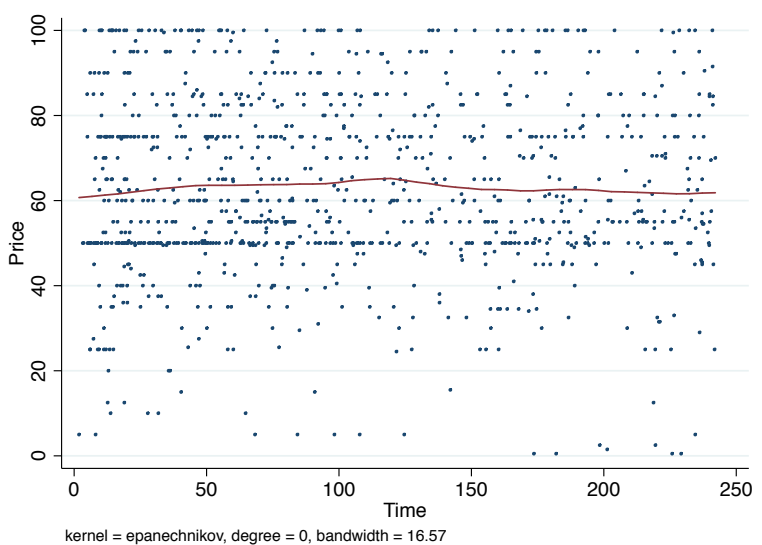

(a) Negative signal

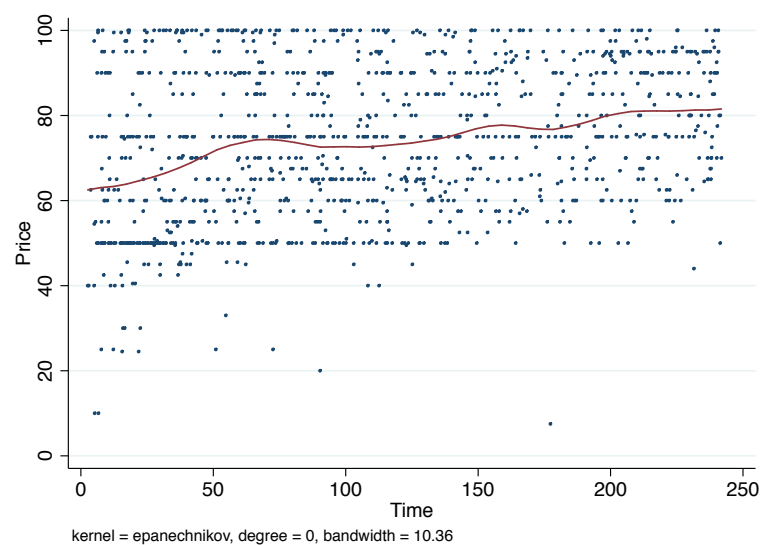

(b) Positive signal

Notes: In each market, participants traded for 4 minutes. The figure shows the correlation between asset prices and past time. We illustrate the time trend with a kernel-weighted local polynomial regression. 
Figure A4: Asymmetric updating in Market condition

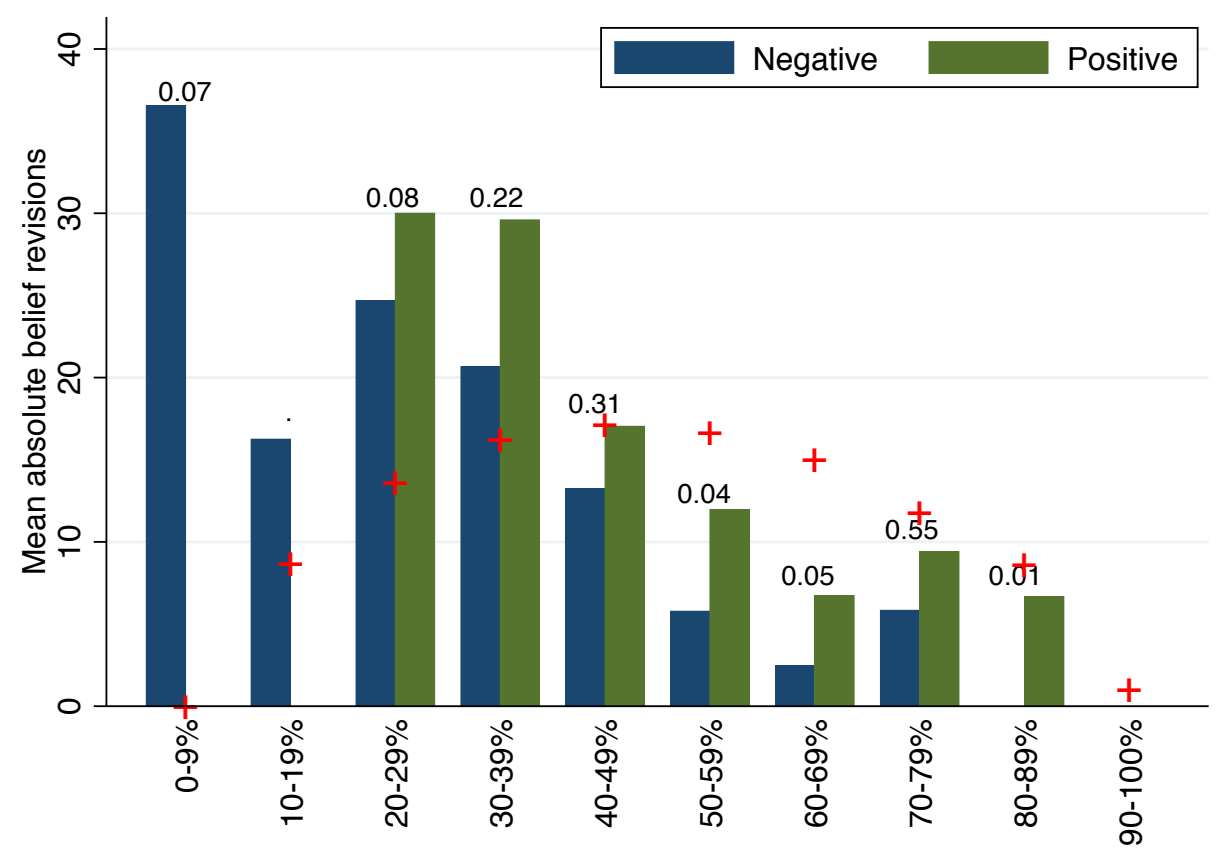

Mean absolute belief revisions by decile of prior belief in being of type equal to the signal received (following Möbius et al., 2017). The number on top of the bars indicate p-values. + indicates the rational benchmark of Bayesian updating. Observations where people updated in the wrong direction are excluded. 


\section{Appendix B: Updating in the Market condition}

In this Appendix, we adapt the framework introduced in Section 2.4 to the Market condition. In particular, we allow the decision makers to update her belief not only in response to the signal from the urn, but also in response to the market prices. We assume that there are two possible signals from the market, a good signal and a bad signal. The decision maker makes two sequential updating decisions. First, she starts with a prior (belief1), and incorporates the signal from the urn, $s_{U, i}$, into her belief (belief2). Second, she starts from the updated belief (belief2) and incorporates the market signal, $s_{M, i}$, into her belief (belief3). We follow Möbius et al. (2017) by modeling the updating behavior with a parameterized version of Bayes rule. The first belief update is captured by:

$\operatorname{logit}\left(\right.$ belief $\left.2_{i}\right)=\delta_{U} \operatorname{logit}\left(\right.$ belief $\left.1_{i}\right)+\beta_{U, L} \lambda_{U, L} \mathbf{1}\left(s_{U, i}=\right.$ neg $)+\beta_{U, H} \lambda_{U, H} \mathbf{1}\left(s_{U, i}=\right.$ pos. $)$ (2)

where $\mathbf{1}\left(s_{U, i}=\right.$ pos. $)$ indicates that the signal from the urn was positive, $\lambda_{U, H}=-\lambda_{U, L}=\ln (2)$ is the log likelihood ratio of a positive signal from the urn, $\delta_{U}$ measures the weight placed on the prior belief and $\beta_{U, L}$ and $\beta_{U, H}$ measures how strong the decision maker react to positive and negative signals from the urn.

The second update is captured by:

$$
\operatorname{logit}\left(\text { belief }_{i}\right)=\delta_{M} \operatorname{logit}\left(\text { belief } 2_{i}\right)+\beta_{M, L} \lambda_{M, L} \mathbf{1}\left(s_{M, i}=\text { neg. }\right)+\beta_{M, H} \lambda_{M, H} \mathbf{1}\left(s_{M, i}=\text { pos. }\right)(3)
$$

where $\mathbf{1}\left(s_{M, i}=\right.$ pos. $)$ indicates that the market signal was positive, $\delta_{M}$ measures the weight placed on the prior belief, $\beta_{M, L}$ and $\beta_{M, H}$ measures how much weight the decision maker puts on the market signal and $\lambda_{M, H}$ is the log likelihood ratio of a positive market signal given the signal from the urn:

$$
\begin{aligned}
& \lambda_{M, L}=\ln \frac{\operatorname{Pr}\left(s_{M, i}=\text { neg. } \mid \text { More points }, s_{U, i}\right)}{\operatorname{Pr}\left(s_{M, i}=\text { neg. } \mid \text { Less points }, s_{U, i}\right)} \\
& \lambda_{M, H}=\ln \frac{\operatorname{Pr}\left(s_{M, i}=\text { pos. } \mid \text { More points }, s_{U, i}\right)}{\operatorname{Pr}\left(s_{M, i}=\text { pos. } \mid \text { Less points }, s_{U, i}\right)} .
\end{aligned}
$$

Note that $\lambda_{M, L}$ is zero if the market signal is perceived as non-informative conditional on the signal from the urn. If $\beta_{M, L} \lambda_{M, L} \neq 0\left(\beta_{M, H} \lambda_{M, H} \neq 0\right)$, the subject perceives the negative (positive) market signals as informative, and incorporates them into her belief. 
Combining equations (2) and (3) results in:

$$
\begin{aligned}
\operatorname{logit}\left(\text { belief } 3_{i}\right)= & \delta_{M} \delta_{U} \operatorname{logit}\left(\text { belief } 1_{i}\right)+\delta_{M} \beta_{U, L} \lambda_{U, L} \mathbf{1}\left(s_{U, i}=\text { neg. }\right)+\delta_{M} \beta_{U, H} \lambda_{U, H} \mathbf{1}\left(s_{U, i}=\text { pos. }\right) \\
& +\beta_{M, L} \lambda_{M, L} \mathbf{1}\left(s_{M, i}=\text { neg. }\right)+\beta_{M, H} \lambda_{M, H} \mathbf{1}\left(s_{M, i}=\text { pos. }\right)
\end{aligned}
$$

In the following, we want to test whether subjects react to a positive and negative market signals, that is, $\beta_{M, L} \lambda_{M, L} \neq 0$ and $\beta_{M, H} \lambda_{M, H} \neq 0$. How should we estimate the parameters of model (4)? First, we need a measure for a good and a bad market signal. We use two different measures:

- $\quad$ Measure 1: bad market signal $=$ the normalized average market price $^{27}$ is lower than a subject's prior belief $\left(\right.$ belief $\left.1_{i}\right)$; good market signal $=$ the normalized average market price is higher than a subject's prior belief.

- $\quad$ Measure 2: bad market signal $=$ the normalized average market price is lower than a subject's estimated belief $2_{i}$ (using the parameters estimated in the Collective condition); good market signal = the normalized average market price is higher than a subject's estimated belief $2_{i}$.

A second challenge is that we can not identify the parameters of interested by only using data from the Market condition. We solve this issue by using data from the Collective condition to estimate the parameters of equation (2), $\delta_{U}, \beta_{U, L}$ and $\beta_{U, H}$ (see Table 4). Using these estimates allows us to identify $\delta_{M}, \beta_{M, L} \lambda_{M, L}$ and $\beta_{M, H} \lambda_{M, H} \cdot{ }^{28}$ We bootstrap estimation of equation (2) (with the Collective condition data) and estimation of equation (3) (with Market condition data) together to calculate standard errors. Table B1 gives the estimates.

We find some evidence that subjects respond to positive market signals by increasing their confidence. However, subjects ignore bad market signals. Subjects thus seem to respond asymmetrically to market prices in a way that helps them to stay (over-)confident. Another interesting finding is that base-rate neglect also applies to the second update, that is, $\delta_{M}<1$. This suggests that a potential explanation for the difference in $\delta_{t}$ between the Market and the

\footnotetext{
${ }^{27}$ The normalized market price is the price to which a risk-neutral trader would buy the asset if she believed that the probability of winning the competition was higher than the price and would sell the asset if she believed that it was lower than the price.

${ }^{28}$ We can not differentiate between $\beta_{M}$ and $\lambda_{M}$. However, this is not necessary to test whether subjects react to a positive and negative market signals, that is, $\beta_{M, L} \lambda_{M, L} \neq 0$ and $\beta_{M, H} \lambda_{M, H} \neq 0$.
} 
Collective condition (see Table 4) is that subjects update twice in the Market condition ( $\delta_{t}=\delta_{M} \delta_{U}$ ) and therefore put less weight on the initial prior. Indeed, multiplying $\hat{\delta}_{U}=0.642$ (as estimated in the Collective condition data, see Table 4) with $\hat{\delta}_{M}=0.747$ (as estimated in the Market condition data, see Table B1) results in $\hat{\delta}_{t}=0.480$ for the sample with a prior belief in $[20,80]$. This is similar to the estimate we find when we estimate the parameters of model (1) in the Market condition (see Table 4, $\delta_{t}=0.455$ ).

Table B1: Updating in response to the market signal

\begin{tabular}{|c|c|c|c|c|c|c|c|c|}
\hline & $\begin{array}{l}\text { Prior in } \\
(0,100)\end{array}$ & $\begin{array}{l}\text { Prior in } \\
{[10,90]}\end{array}$ & $\begin{array}{l}\text { Prior in } \\
{[20,80]}\end{array}$ & $\begin{array}{l}\text { Prior in } \\
{[30,70]}\end{array}$ & $\begin{array}{l}\text { Prior in } \\
{[40,60]}\end{array}$ & $\begin{array}{l}\text { Sub- } \\
\text { sample } 1\end{array}$ & $\begin{array}{l}\text { Sub- } \\
\text { sample } 2\end{array}$ & $\begin{array}{l}\text { Sub- } \\
\text { sample } 3\end{array}$ \\
\hline & \multicolumn{8}{|c|}{ Measure 1} \\
\hline \multirow[t]{2}{*}{$\widehat{\boldsymbol{\delta}}_{M}$} & $0.825 * * *$ & $0.708 * * *$ & $0.747 * * *$ & $0.740 * * *$ & $0.707 * * *$ & $0.907 * * *$ & $0.771 * * *$ & $0.785 * * *$ \\
\hline & $(0.124)$ & $(0.062)$ & $(0.065)$ & $(0.073)$ & $(0.095)$ & $(0.137)$ & $(0.085)$ & $(0.084)$ \\
\hline \multirow[t]{2}{*}{$\widehat{\boldsymbol{\beta}}_{U, L} \hat{\lambda}_{U, L}$} & -0.057 & 0.000 & -0.017 & -0.044 & 0.053 & -0.005 & 0.016 & -0.023 \\
\hline & $(0.088)$ & $(0.081)$ & $(0.085)$ & $(0.079)$ & $(0.068)$ & $(0.099)$ & $(0.096)$ & $(0.101)$ \\
\hline \multirow[t]{2}{*}{$\widehat{\boldsymbol{\beta}}_{M, H} \hat{\lambda}_{M, H}$} & 0.113 & $0.141 * * *$ & $0.129 * * *$ & $0.118 * *$ & $0.108^{* *}$ & 0.065 & $0.141^{* *}$ & $0.106^{* *}$ \\
\hline & $(0.078)$ & $(0.042)$ & $(0.042)$ & $(0.048)$ & $(0.044)$ & $(0.082)$ & $(0.055)$ & $(0.047)$ \\
\hline \multirow[t]{2}{*}{$\mathbf{N}$} & 453 & 448 & 441 & 394 & 303 & 377 & 338 & 334 \\
\hline & \multicolumn{8}{|c|}{ Measure 2} \\
\hline \multirow[t]{2}{*}{$\widehat{\boldsymbol{\delta}}_{M}$} & $0.841 * * *$ & $0.723 * * *$ & $0.758 * * *$ & $0.770 * * *$ & $0.716^{* * *}$ & $0.917 * * *$ & $0.783 * * *$ & $0.801 * * *$ \\
\hline & $(0.126)$ & $(0.060)$ & $(0.064)$ & $(0.072)$ & $(0.092)$ & $(0.138)$ & $(0.087)$ & $(0.081)$ \\
\hline \multirow[t]{2}{*}{$\widehat{\boldsymbol{\beta}}_{U, L} \hat{\lambda}_{U, L}$} & -0.058 & 0.024 & 0.036 & -0.016 & 0.112 & -0.014 & 0.051 & 0.017 \\
\hline & $(0.134)$ & $(0.120)$ & $(0.106)$ & $(0.102)$ & $(0.076)$ & $(0.139)$ & $(0.137)$ & $(0.128)$ \\
\hline \multirow[t]{2}{*}{$\widehat{\boldsymbol{\beta}}_{M, H} \hat{\lambda}_{M, H}$} & 0.094 & $0.119 * * *$ & $0.101 * *$ & $0.098 * *$ & $0.095 * *$ & 0.060 & $0.117^{* *}$ & $0.080^{*}$ \\
\hline & $(0.068)$ & $(0.043)$ & $(0.045)$ & $(0.047)$ & $(0.044)$ & $(0.071)$ & $(0.049)$ & $(0.044)$ \\
\hline $\mathbf{N}$ & 453 & 448 & 441 & 394 & 303 & 377 & 338 & 334 \\
\hline
\end{tabular}

Note: Estimated coefficients of model (1). Observations where people updated in the wrong direction or with a prior of 0 percent of 100 percent are excluded are excluded. "Prior in [10,90]" means that the sample is restricted to observations with a prior in between 10 percent and 90 percent. Subsample 1 restricts the sample to subjects that never updated in the wrong direction (in the 4 rounds). Subsample 2 restricts Subsample 1 to subjects who updated their beliefs at least once (the subsample explored in Möbius et al. (2017)). Subsample 3 restricts Subsample 2 to observations with a prior in [20,80]. Bootstrapped standard errors (over the two-stage estimation), clustered at matched-individual/group level; Standard errors in parentheses; $*-p<0.1 ; * *-p$ $<0.05$; *** $-p<0.01$. 


\section{Appendix C: Additional figures}

Figure C1: Task interface Individual condition

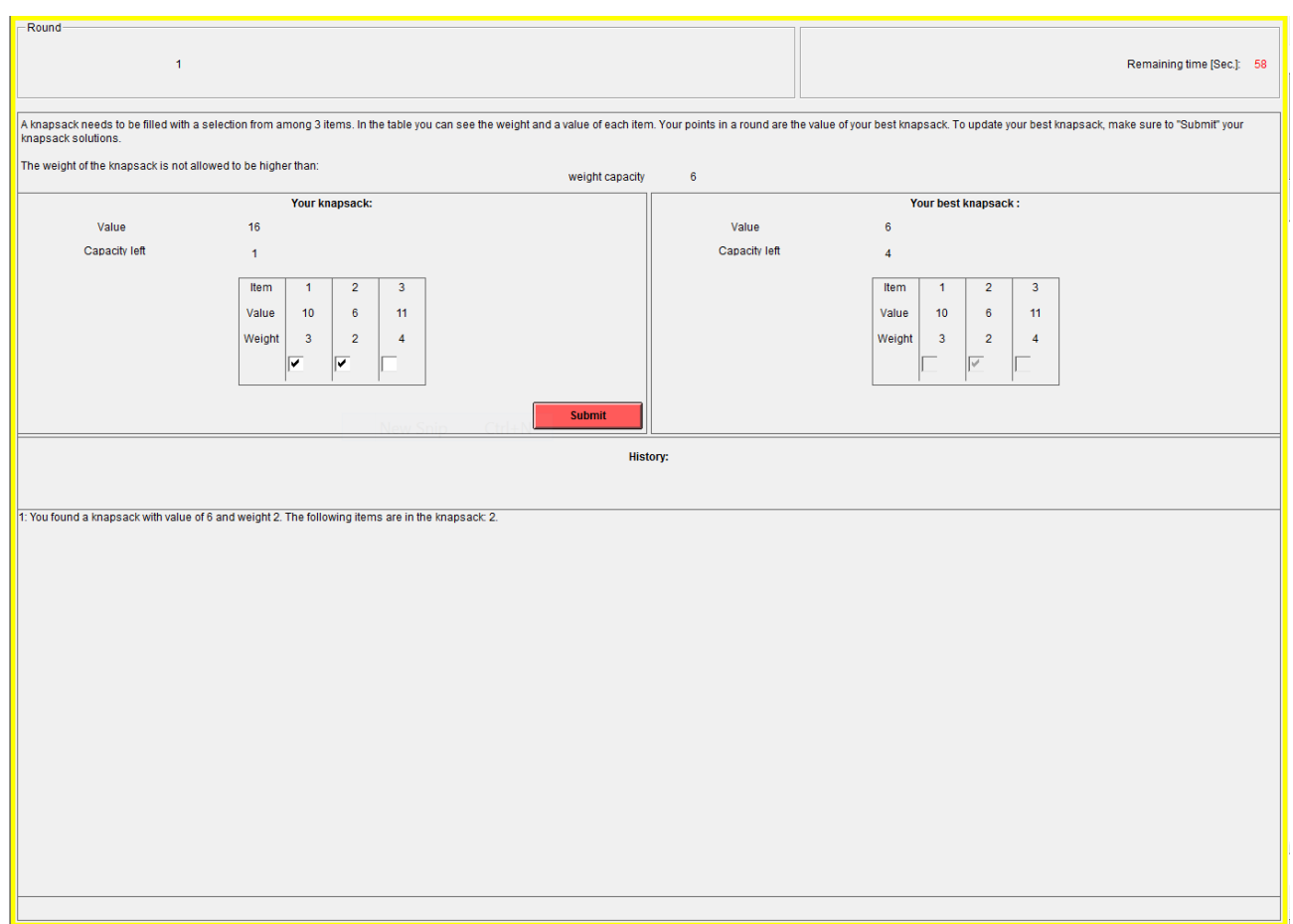

Figure C2: Task interface Collective and Market condition

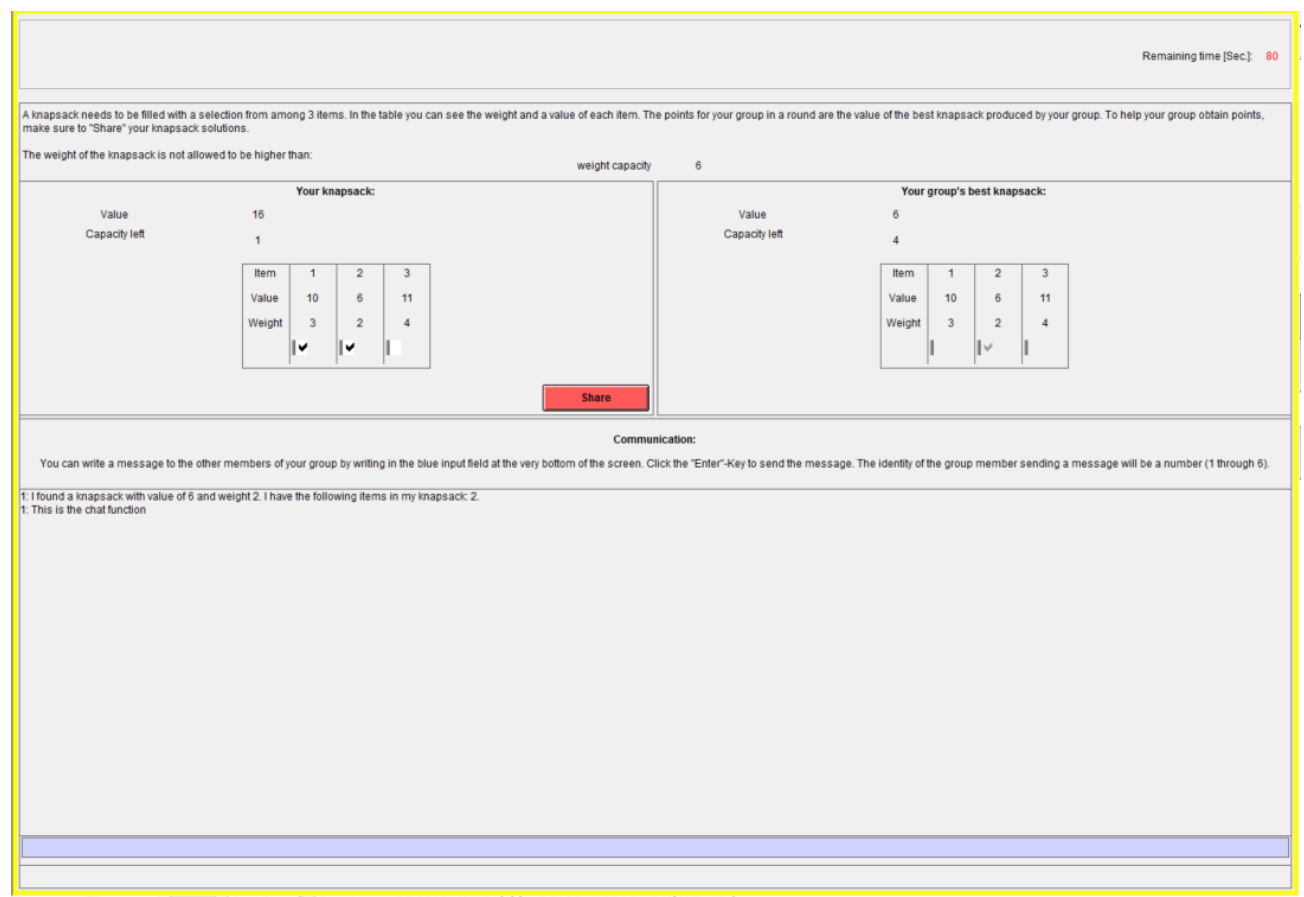


Figure C3: Market interface

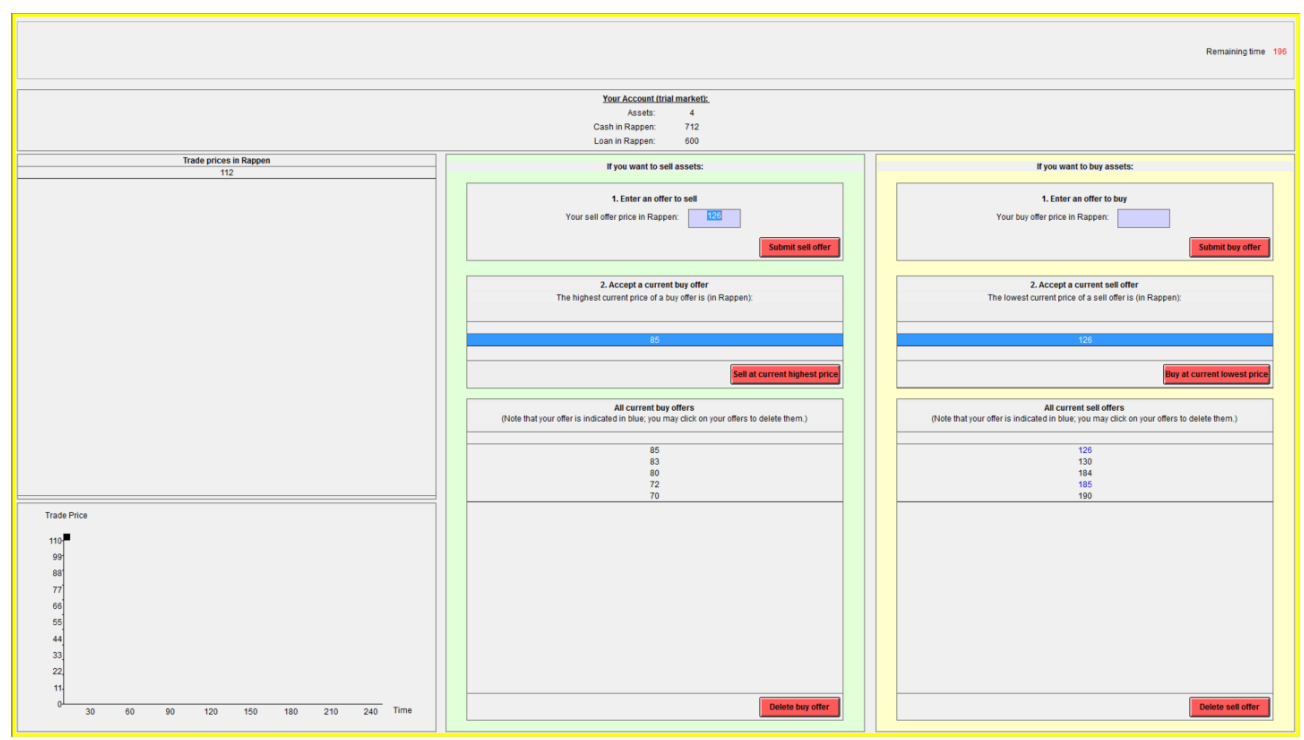




\section{Appendix D: Instructions}

\section{Individual condition}

\section{Initial Instructions}

Please do NOT click the OK button on the screen until the experimenter asks you to do so.

Thank you for participating. During this experiment, you will be asked to make several decisions that will impact the amount of money that you will earn. It is thus very important that you read the instructions carefully, and that you make your decisions with care. If you have any questions, please raise your hand and wait for a staff member to come and help you.

Talking with the other participants is strictly forbidden during the study. The use of your mobile phone is also forbidden. Violation of the rules will lead to exclusion from the study and loss of all of the associated payments.

According to the scientific standards for lab experiments at the Decision Science Laboratory, we are not allowed to lie to you or deceive you at any point in time. Also note that all the information gathered during this experiment is stored in a strictly anonymous manner. The experimenters will not link your behavior to your identity.

The experiment lasts about 75 minutes and is divided into multiple rounds. We will now proceed to the Instructions on the next page. 


\section{Instructions: Overview}

\section{The other participant}

In this experiment, you are randomly matched with another participant, called the other participant. You and the same other participant will be paired together in every round of the experiment.

\section{Overview of the experiment}

The experiment consists of multiple rounds. Each round follows the same procedure:

1. You will solve a task, a so-called knapsack problem. The other participant will solve the same knapsack problem under exactly the same circumstances as you.

2. After you are done with the task, you will receive points for your solution, depending on how close you were to the optimal solution. The other participant will also receive points for his or her solution. Then, the computer will compare your points with those of the other participant, to determine part of your earnings in this experiment.

3. You will be asked to estimate the percent chance that you have more points than the other participant in that round.

4. You will receive a clue about your relative performance in that round.

5. You will be asked, once more, to estimate the percent chance that you have more points than the other participant in that round.

Every round will proceed through these 5 parts. In every round, you will solve a new knapsack problem. Therefore, your points (and those of the other participant) are likely to vary across rounds. Everything else stays consistent across rounds.

\section{Your compensation}

You will be paid for your performance on the task, and for your estimates of the percent chance that you have more points than the other participant.

Earnings from task performance: Each participant receives an initial endowment of $25 \mathrm{CHF}$. At the end of the experiment, one round will be randomly selected. Each round has the same probability to be selected. For this round, the computer will compare the points obtained by you and the points obtained by the other participant. The program will then transfer 15 CHF from the endowment of the participant with fewer points to the participant with more points. If both participants have the same number of points, the receiver of the transfer is the participant that took less time to find his or her solution.

Thus, the final endowment from the task of the participant with fewer points will be $10 \mathrm{CHF}$ and the final endowment of the participant with more points will be $40 \mathrm{CHF}$. The final endowment will be paid to you at the end of the experiment.

Earnings from the estimates: The computer will also randomly select another, different round, and will randomly select one of your two estimates in this round. Each of your estimates, other than the ones in the round selected by the computer to count for earnings from task performance, is equally likely to be chosen. The computer will also determine a payment based on the accuracy of your estimates. We will explain later, in detail, how this payment is determined.

We will now explain the experiment in more detail. 


\section{The knapsack problem}

A knapsack problem is a puzzle where a knapsack needs to be filled with a selection from among a number of items. Each item has a weight and a value. The knapsack has a weight capacity. You can choose to put items in the knapsack, up to the weight capacity of the knapsack. Your goal is to maximize the total value (sum of values) of the items that can fit in the knapsack.

Example 1: Here is an example of a simple knapsack problem. There are three items with the following weights and values.

\begin{tabular}{ccc}
\hline & Weight & Value \\
\hline $\mathbf{1}$ & 3 & 10 \\
$\mathbf{2}$ & 2 & 6 \\
$\mathbf{3}$ & 4 & 11 \\
\hline
\end{tabular}

The weight capacity (maximum weight) of the knapsack in this example is 6 . We can try all combinations, determine whether they fit, and if so, we should pick the best one.

\begin{tabular}{llll}
\hline $\begin{array}{l}\text { Items } \\
\text { “in" }\end{array}$ & $\begin{array}{l}\text { Total } \\
\text { Weight }\end{array}$ & $\begin{array}{l}\text { Fits? } \\
(\mathbf{s})\end{array}$ & $\begin{array}{l}\text { Total } \\
\text { Value }\end{array}$ \\
\hline $\mathbf{1}$ & 3 & Yes & 10 \\
$\mathbf{2}$ & 2 & Yes & 6 \\
$\mathbf{3}$ & 4 & Yes & 11 \\
$\mathbf{1 , 2}$ & 5 & Yes & 16 \\
$\mathbf{1 , 3}$ & 7 & No & - \\
$\mathbf{2 , 3}$ & 6 & Yes & 17 \\
$\mathbf{1 , 2 , 3}$ & 9 & No & - \\
\hline
\end{tabular}

The best knapsack is obtained by choosing items 2 and 3 . This gives a total value of $17(=6+11)$ and a total weight of $6(=2+4)$.

\section{How your points are determined}

In each round, you will work on a knapsack problem. At the end of the round, your points equal the value of the best knapsack found by you. The best knapsack is the knapsack with the most value that you find in that round. Remember that your points (and those of the other participant) will determine your earnings from the task.

In each round, you will first see the specific knapsack problem, and will get 90 seconds to think about how to tackle this task. After that, you will get another 60 seconds to work on the knapsack problem. During that time, you can fill your knapsack and submit your knapsack solutions.

\section{Filling your knapsack}

Please look now at the separate sheet "Handout: overview knapsack screen." For the moment, only look at Panel A (in green) and Panel B (in blue). Here you can see how the knapsack problem from the above example would be displayed on your screen. The weight capacity is displayed at the center of Panel A. The upper-right corner of Panel A displays the time remaining. In the table in 
Panel B, you see the value and the weight of the items. By checking the checkbox below an item, you add this item to your knapsack. By checking the checkbox again, you delete this item from your knapsack. Note that during the 90 -second interval during which you can think about how to tackle this task, you cannot add items to your knapsack. The total value and remaining capacity (capacity minus weight of the items already in the knapsack) of your current knapsack are displayed at the center of Panel B. The button "Submit" will be explained later.

\section{Your best knapsack}

On your screen, you will always see the value, weight and content of your best knapsack. Remember, your best knapsack is the knapsack with the most value that you have found so far. This is illustrated in Panel C (in red) in "Handout: overview knapsack screen." In this example, the best knapsack found so far consists only of item 2 and has a value of 6.

If you find a knapsack that has more value, you can click the "Submit" button (in Panel B). Then, your best knapsack will be replaced by your current knapsack. The computer will only replace the previous best knapsack if your current knapsack has a higher value, and its weight is lower than (or equal to) the weight capacity. You can only submit your knapsack during the 60-second work period.

Note that your knapsack will not be submitted automatically. Remember that your points in a round equal your best knapsack at the end of the work period. For you to make progress, make sure to submit your knapsack solutions whenever you find a better one.

\section{Trial period}

Before proceeding with the rest of the instructions, you will have some time to familiarize yourself with the computer interface that you will use to solve knapsack problems. For this purpose, you will see a trial knapsack problem on your screen, and you will have 90 seconds to test how the interface works. This trial has no influence on your earnings.

If you have any questions during this trial period, please raise your hand and wait for a staff member to come and help you. 


\section{Estimate of relative performance}

Remember that in every round of the experiment, after you work on a solution to the knapsack problem, you will provide an estimate of the percent chance that you have more points in that round than the other participant. You will enter the estimate by typing a number into an input box. You can enter any number between 0 percent and 100 percent. To give some examples of what these percentages mean:

- 50 percent means that you think it is equally likely that you have fewer or more points than the other participant,

- 0 percent means that you are certain that you have fewer points than the other participant and

- 100 percent means that you are certain that you have more points than the other participant.

\section{How does accuracy determine the earnings from the estimates?}

We will now explain to you in detail how your estimates will influence your earnings in this experiment. As explained before, at the end of the experiment one of your estimates will be randomly selected and your payment will be determined according to the accuracy of this estimate. Lets call your estimate of the percent chance that you have more points than the other participant, $p$. Your payment depends on this estimate and on whether you actually have fewer or more points in the selected round:

If you have more points: $\quad$ Earnings (in CHF) $=10-10 *(1-p / 100)^{2}$ If you have fewer points: $\quad$ Earnings (in $C H F)=10-10^{*}(p / 100)^{2}$

The range of your payoffs is from $0 \mathrm{CHF}$ to $10 \mathrm{CHF}$. These formulas may appear complicated, but what they mean for you is very simple: You can expect to earn the most money when you honestly report your best guess about the percent chance that you have more points and avoid making estimates that are too high or too low. The following examples illustrate how these formulas make sure that you will earn more money by making more accurate estimates.

Example: Suppose that, at the end of the experiment, you learn that you have more points than the other participant in the chosen round.

- Suppose your estimate was $p=60$ percent. Then your earnings are $10-10 *(1-60 / 100)^{2} \mathrm{CHF}=8.4 \mathrm{CHF}$.

- Suppose your estimate was $p=40$ percent. Then your earnings are $10-10 *(1-40 / 100)^{2} \mathrm{CHF}=6.4 \mathrm{CHF}$.

Suppose that, at the end of the experiment, you learn that you have fewer points than the other participant in the chosen round.

- Suppose your estimate was $p=60$ percent. Then your earnings are $10-10 *(60 / 100)^{2} \mathrm{CHF}=6.4 \mathrm{CHF}$.

- Suppose your estimate was $p=40$ percent. Then your earnings are $10-10 *(40 / 100)^{2} \mathrm{CHF}=8.4 \mathrm{CHF}$.

Note that making an estimate that is too extreme-of either 0 percent or 100 percent-can earn you $10 \mathrm{CHF}$ if you are right, but will earn you $0 \mathrm{CHF}$ if you are wrong.

If both participants have the same number of points in a round, then the participant that used less time to find his or her solution is considered have "more points." 


\section{Clues about relative performance}

In every round, after you indicate your estimate the first time, you will then receive a clue about whether or not you have more points than the other participant in that round.

\section{What is a clue about relative performance?}

The clue informs you about your relative performance. Specifically, it gives you an indication about whether you have fewer or more points in that round, to help you estimate the percent chance that you have more points. However, the clue does not perfectly reveal which participant did better.

In the following, we explain how the clue is generated:

- There is an Urn with 3 balls, determined as follows:

- 2 balls correspond to the participant with more points, and

- 1 ball corresponds to the participant with fewer points.

- The computer will randomly draw one ball out of the urn. Thus, each ball has the same chance to be drawn, namely $1 / 3$.

- The computer will tell you whether the drawn ball corresponds to you or to the other participant.

Note that this procedure means that a ball corresponding to the participant that actually has more points has a $2 / 3$ chance to be selected, while a ball corresponding to the participant that has fewer points has a $1 / 3$ chance to be selected. After you receive this clue, you again have to estimate the percent chance that you have more points than the other participant.

Note that the urn is newly filled after every round, according to the points received by you and the points received by the other participant in the knapsack problem in that round.

We will now proceed with several understanding questions. Please proceed through these questions at your own pace. If you have any questions, please raise your hand and wait for a staff member to come and help you. Once you are finished, please wait for everyone to complete the questions. 


\section{Handout: overview knapsack screen}

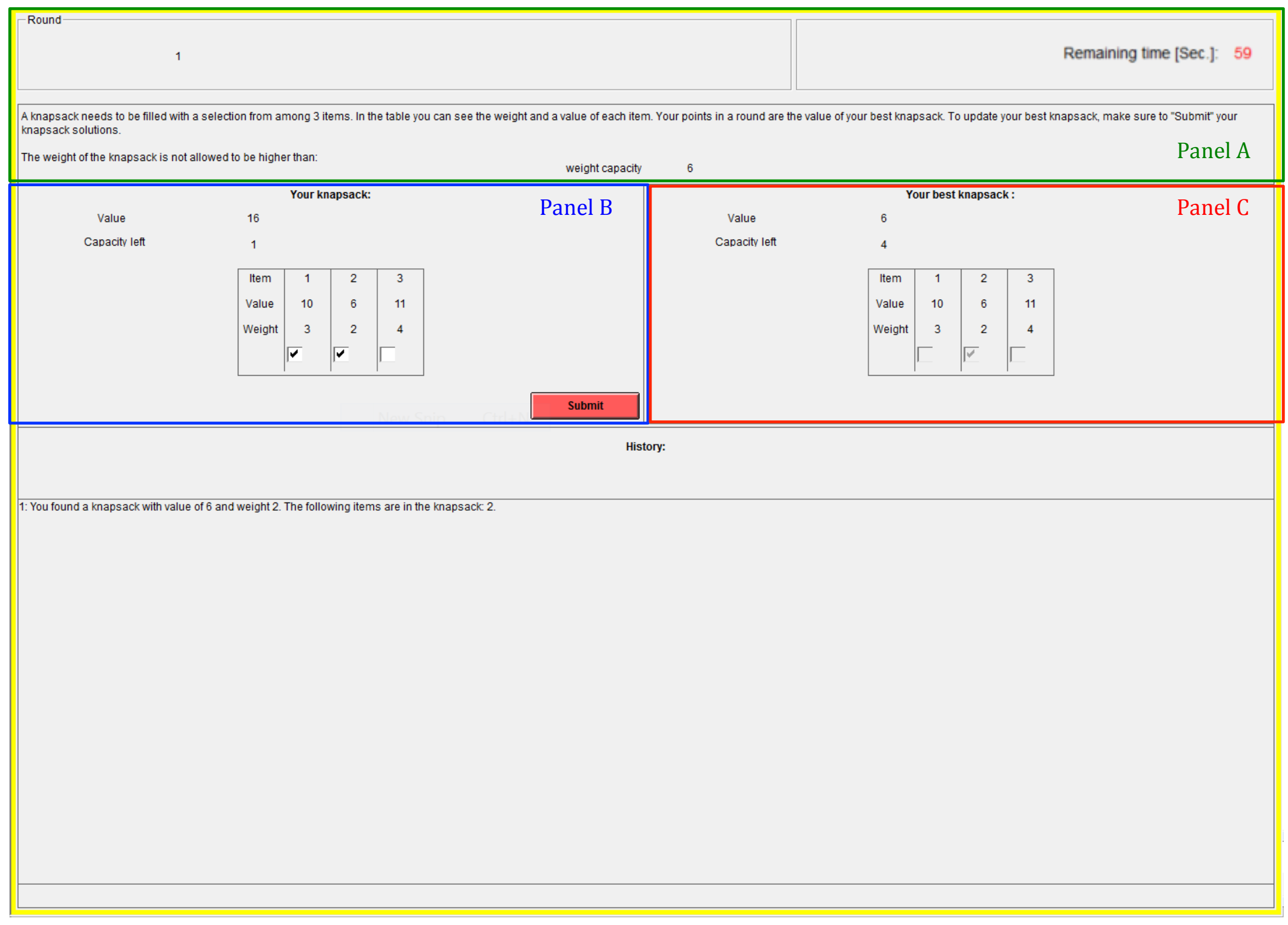




\section{Collective condition}

\section{Initial Instructions}

Please do NOT click the OK button on the screen until the experimenter asks you to do so.

Thank you for participating. During this experiment, you will be asked to make several decisions that will impact the amount of money that you will earn. It is thus very important that you read the instructions carefully, and that you make your decisions with care. If you have any questions, please raise your hand and wait for a staff member to come and help you.

Talking with the other participants is strictly forbidden during the study. The use of your mobile phone is also forbidden. Violation of the rules will lead to exclusion from the study and loss of all of the associated payments.

According to the scientific standards for lab experiments at the Decision Science Laboratory, we are not allowed to lie to you or deceive you at any point in time. Also note that all the information gathered during this experiment is stored in a strictly anonymous manner. The experimenters will not link your behavior to your identity.

The experiment lasts about 75 minutes and is divided into multiple rounds. We will now proceed to the Instructions on the next page. 


\section{Instructions: Overview}

\section{Your group and the other group}

In this experiment, you are randomly paired with 5 other participants. You and these other participants form a 6-person group, called your group. You will be in the same group in every round of the experiment. Your group is randomly matched with another group of the same size, called the other group. Your group and the same other group will be paired together in every round of the experiment.

\section{Overview of the experiment}

The experiment consists of multiple rounds. Each round follows the same procedure:

1. Your group will solve a task together, a so-called knapsack problem. To find the best solution to this problem, you can communicate with the other members of your group via a chatbox. The other group will solve the same knapsack problem under exactly the same circumstances as you.

2. After your group is done with the task, your group will receive points for your solution, depending on how close you were to the optimal solution. The other group will also receive points for their solution. Then, the computer will compare your group's points with those of the other group, to determine part of your earnings in this experiment.

3. You will be asked to estimate the percent chance that your group has more points than the other group in that round.

4. You will receive a clue about the relative performance of your group in that round.

5. You will be asked, once more, to estimate the percent chance that your group has more points than the other group in that round.

Every round will proceed through these 5 parts. In every round, your group will solve a new knapsack problem. Therefore, your group's points (and those of the other group) are likely to vary across rounds. Everything else stays consistent across rounds.

\section{Your compensation}

You will be paid for your performance on the task, and for your estimates of the percent chance that your group has more points than the other group.

Earnings from task performance: Each group receives an initial endowment of $150 \mathrm{CHF}$. At the end of the experiment, one round will be randomly selected. Each round has the same probability to be selected. For this round, the computer will compare the points obtained by your group and the points obtained by the other group. The program will then transfer $90 \mathrm{CHF}$ from the endowment of the group with fewer points to the group with more points. If both groups have the same number of points, the receiver of the transfer is the group that took less time to find their solution.

Thus, the final endowment from the task of the group with fewer points will be $60 \mathrm{CHF}$ and the final endowment of the group with more points will be $240 \mathrm{CHF}$. The final endowment of your group will then be paid in equal shares to each member at the end of the experiment. So, if your group has more points than the other group, you will receive $240 \mathrm{CHF} / 6=40 \mathrm{CHF}$, and if your group has fewer points, you will receive $60 \mathrm{CHF} / 6=10$ CHF. 
Earnings from the estimates: The computer will also randomly select another, different round, and will randomly select one of your two estimates in this round. Each of your estimates, other than the ones in the round selected by the computer to count for earnings from task performance, is equally likely to be chosen. The computer will also determine a payment based on the accuracy of your estimates. We will explain later, in detail, how this payment is determined.

We will now explain the experiment in more detail. 


\section{The knapsack problem}

A knapsack problem is a puzzle where a knapsack needs to be filled with a selection from among a number of items. Each item has a weight and a value. The knapsack has a weight capacity. You can choose to put items in the knapsack, up to the weight capacity of the knapsack. Your group's goal is to maximize the total value (sum of values) of the items that can fit in the knapsack.

Example 1: Here is an example of a simple knapsack problem. There are three items with the following weights and values.

\begin{tabular}{ccc}
\hline & Weight & Value \\
\hline $\mathbf{1}$ & 3 & 10 \\
$\mathbf{2}$ & 2 & 6 \\
$\mathbf{3}$ & 4 & 11 \\
\hline
\end{tabular}

The weight capacity (maximum weight) of the knapsack in this example is 6 . We can try all combinations, determine whether they fit, and if so, we should pick the best one.

\begin{tabular}{llll}
\hline $\begin{array}{l}\text { Items } \\
\text { “in" }\end{array}$ & $\begin{array}{l}\text { Total } \\
\text { Weight }\end{array}$ & $\begin{array}{l}\text { Fits? } \\
(\leq \mathbf{6})\end{array}$ & $\begin{array}{l}\text { Total } \\
\text { Value }\end{array}$ \\
\hline $\mathbf{1}$ & 3 & Yes & 10 \\
$\mathbf{2}$ & 2 & Yes & 6 \\
$\mathbf{3}$ & 4 & Yes & 11 \\
$\mathbf{1 , 2}$ & 5 & Yes & 16 \\
$\mathbf{1 , 3}$ & 7 & No & - \\
$\mathbf{2 , 3}$ & 6 & Yes & 17 \\
$\mathbf{1 , 2 , 3}$ & 9 & No & - \\
\hline
\end{tabular}

The best knapsack is obtained by choosing items 2 and 3 . This gives a total value of 17 $(=6+11)$ and a total weight of $6(=2+4)$.

\section{How your group's points are determined}

In each round, your group will work together on a knapsack problem. At the end of the round, your group's points equal the value of the best knapsack found by your group. The best knapsack is the knapsack with the most value that your group finds in that round. Remember that your group's points (and those of the other group) will determine your earnings from the task.

In each round, your group will first see the specific knapsack problem, and will get 90 seconds to discuss how to tackle this task using the chatbox. After that, your group will get another 60 seconds to work on the knapsack problem, while still having access to the chatbox. During that time, you can fill your knapsack and share your knapsack solutions with the group.

\section{Filling your knapsack}

Please look now at the separate sheet "Handout: overview knapsack screen." For the moment, only look at Panel A (in green) and Panel B (in blue). Here you can see how the knapsack problem from the above example would be displayed on your screen. The weight capacity is displayed at the center of Panel A. The upper-right corner of Panel A 
displays the time remaining. In the table in Panel B, you see the value and the weight of the items. By checking the checkbox below an item, you add this item to your knapsack. By checking the checkbox again, you delete this item from your knapsack. Note that during the 90-second interval during which your group can discuss how to tackle this task, you cannot add items to your knapsack. The total value and remaining capacity (capacity minus weight of the items already in the knapsack) of your current knapsack are displayed at the center of Panel B. The button "Share" will be explained later.

\section{Your group's best knapsack}

On your screen, you will always see the value, weight and content of your group's best knapsack. Remember, your group's best knapsack is the knapsack with the most value that your group has found so far. This is illustrated in Panel C (in red) in "Handout: overview knapsack screen." In this example, the best knapsack found so far in your group consists only of item 2 and has a value of 6 .

If you find a knapsack that has more value, you can click the "Share" button (in Panel B). Then, your group's best knapsack will be replaced by your current knapsack. The computer will only replace the previous best knapsack if your current knapsack has a higher value, and its weight is lower than (or equal to) the weight capacity. You can only submit your knapsack during the 60-second work period.

Note that your knapsack will not be submitted automatically. Remember that your group's points in a round equal your group's best knapsack at the end of the work period. For your group to make progress, make sure to share your knapsack solutions whenever you find a better one.

\section{Communication}

Throughout the process, you can communicate through a chatbox. You can see the chatbox in Panel D (in orange) in "Handout: overview knapsack screen." You can write a message to the other members of your group by writing in the blue input field at the very bottom of the screen. Click the "Enter" Key to send the message. The identity of the group member sending a message will be represented by a number (1 through 6).

The "Share" button not only replaces the current best knapsack if your knapsack has a higher value; this button also allows you to communicate any solutions you want to share. When you click the "Share" button, your current knapsack (value, weight and content) will be posted in the chatbox, so the other members of your group can see your knapsack. The following message will appear in the chatbox: "I found a knapsack with value of [VALUE] and weight [WEIGHT]. I have the following items in my knapsack: [CONTENT]." The computer will only allow you to share your knapsack if its weight is lower than (or equal to) the weight capacity.

\section{Trial period}

Before proceeding with the rest of the instructions, you will have some time to familiarize yourself with the computer interface that you will use to solve knapsack problems and communicate with your group. For this purpose, you will see a trial knapsack problem on your screen, and you will have 90 seconds to test how the interface works. This trial has no influence on your earnings. During the trial, you cannot communicate with the other members of your team, but you can enter messages in the chatbox to see how they will appear.

If you have any questions during this trial period, please raise your hand and wait for a staff member to come and help you. 


\section{Estimate of relative performance}

Remember that in every round of the experiment, after your group works on a solution to the knapsack problem, you will provide an estimate of the percent chance that your group has more points in that round than the other group. You will enter the estimate by typing a number into an input box. You can enter any number between 0 percent and 100 percent. To give some examples of what these percentages mean:

- $\mathbf{5 0}$ percent means that you think it is equally likely that your group has fewer or more points than the other group,

- 0 percent means that you are certain that your group has fewer points than the other group, and

- 100 percent means that you are certain that your group has more points than the other group.

\section{How does accuracy determine the earnings from the estimates?}

We will now explain to you in detail how your estimates will influence your earnings in this experiment. As explained before, at the end of the experiment one of your estimates will be randomly selected and your payment will be determined according to the accuracy of this estimate. Lets call your estimate of the percent chance that your group has more points than the other group, $p$. Your payment depends on this estimate and on whether your group actually has fewer or more points in the selected round:

If your group has more points: If your group has fewer points:

$$
\begin{aligned}
& \text { Earnings }(\text { in } C H F)=10-10 *(1-p / 100)^{2} \\
& \text { Earnings }(\text { in } C H F)=10-10 *(p / 100)^{2}
\end{aligned}
$$

The range of your payoffs is from $0 \mathrm{CHF}$ to $10 \mathrm{CHF}$. These formulas may appear complicated, but what they mean for you is very simple: You can expect to earn the most money when you honestly report your best guess about the percent chance that your group has more points and avoid making estimates that are too high or too low. The following examples illustrate how these formulas make sure that you will earn more money by making more accurate estimates.

Example: Suppose that, at the end of the experiment, you learn that your group has more points than the other group in the chosen round.

- Suppose your estimate was $p=60$ percent. Then your earnings are $10-10 *(1-60 / 100)^{2} \mathrm{CHF}=8.4 \mathrm{CHF}$.

- Suppose your estimate was $p=40$ percent. Then your earnings are $10-10 *(1-40 / 100)^{2} \mathrm{CHF}=6.4 \mathrm{CHF}$.

Suppose that, at the end of the experiment, you learn that your group has fewer points than the other group in the chosen round.

- Suppose your estimate was $p=60$ percent. Then your earnings are $10-10 *(60 / 100)^{2} \mathrm{CHF}=6.4 \mathrm{CHF}$.

- Suppose your estimate was $p=40$ percent. Then your earnings are $10-10 *(40 / 100)^{2} \mathrm{CHF}=8.4 \mathrm{CHF}$.

Note that making an estimate that is too extreme-of either 0 percent or 100 percentcan earn you $10 \mathrm{CHF}$ if you are right, but will earn you $0 \mathrm{CHF}$ if you are wrong.

If both groups have the same number of points in a round, then the group that used less time to find their solution is considered to have "more points." 


\section{Clues about relative performance}

In every round, after you indicate your estimate the first time, you will then receive a clue about whether or not your group has more points than the other group in that round.

\section{What is a clue about relative performance?}

The clue informs you about your group's relative performance. Specifically, it gives you an indication about whether your group has fewer or more points in that round, to help you estimate the percent chance that your group has more points. However, the clue does not perfectly reveal which group did better.

In the following, we explain how the clue is generated:

- There is an Urn with 3 balls, determined as follows:

- 2 balls correspond to the group with more points, and

- 1 ball corresponds to the group with fewer points.

- The computer will randomly draw one ball out of the urn. Thus, each ball has the same chance to be drawn, namely $1 / 3$.

- The computer will tell every member of your group whether the drawn ball corresponds to your group or to the other group. Every member of your group will receive the same clue.

Note that this procedure means that a ball corresponding to the group that actually has more points has a $2 / 3$ chance to be selected, while a ball corresponding to the group that has fewer points has a $1 / 3$ chance to be selected. After you receive this clue, you again have to estimate the percent chance that your group has more points than the other group.

Note that the urn is newly filled after every round, according to the points received by your group and the points received by the other group in the knapsack problem in that round.

We will now proceed with several understanding questions. Please proceed through these questions at your own pace. If you have any questions, please raise your hand and wait for a staff member to come and help you. Once you are finished, please wait for everyone to complete the questions. 


\section{Handout: overview knapsack screen}

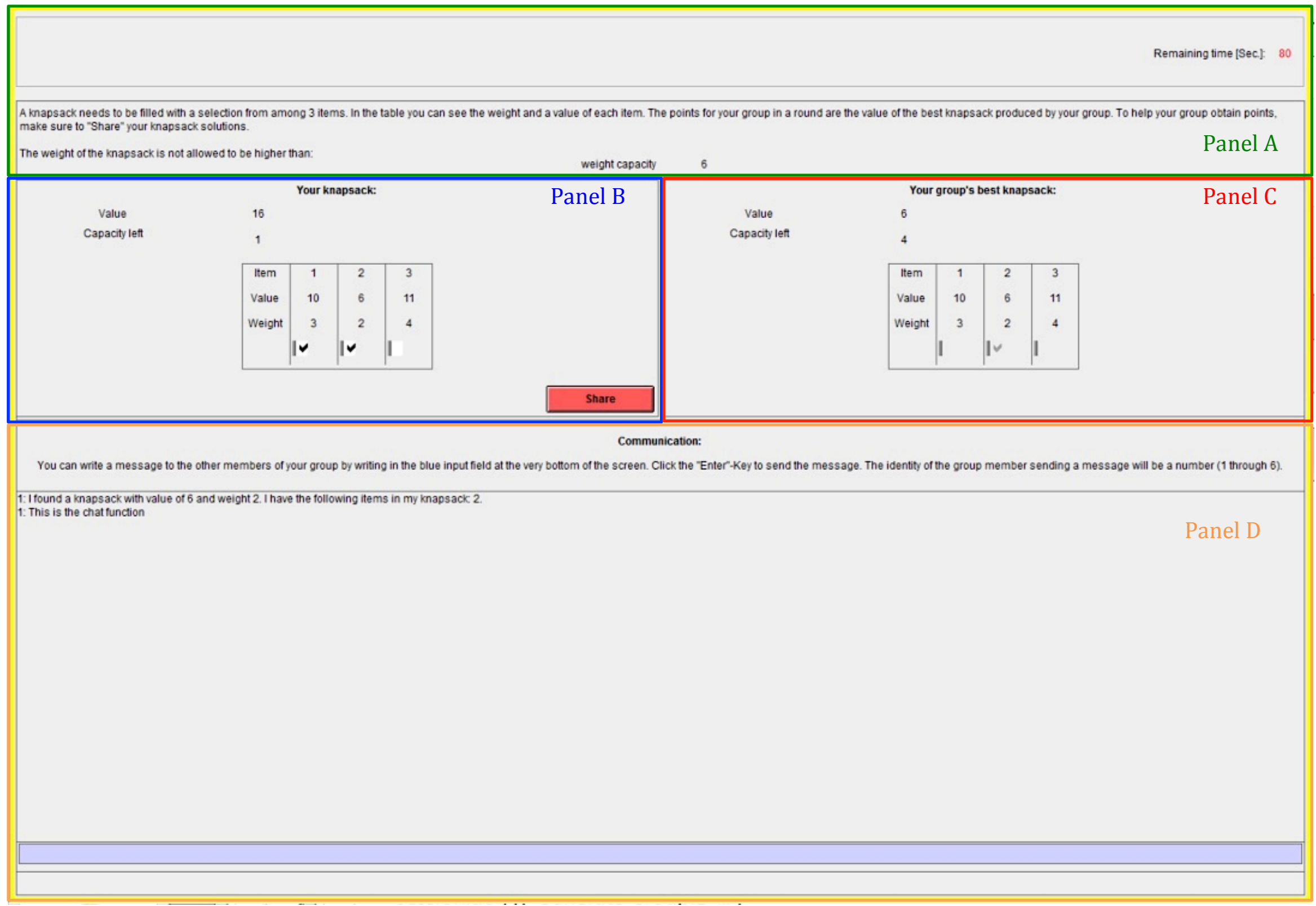




\section{Initial Instructions}

Please do NOT click the OK button on the screen until the experimenter asks you to do so.

Thank you for participating. During this experiment, you will be asked to make several decisions that will impact the amount of money that you will earn. It is thus very important that you read the instructions carefully, and that you make your decisions with care. If you have any questions, please raise your hand and wait for a staff member to come and help you.

Talking with the other participants is strictly forbidden during the study. The use of your mobile phone is also forbidden. Violation of the rules will lead to exclusion from the study and loss of all of the associated payments.

According to the scientific standards for lab experiments at the Decision Science Laboratory, we are not allowed to lie to you or deceive you at any point in time. Also note that all the information gathered during this experiment is stored in a strictly anonymous manner. The experimenters will not link your behavior to your identity.

The experiment lasts about 120 minutes and is divided into multiple rounds. We will now proceed to the Instructions on the next page. 


\section{Instructions: Overview}

\section{Your group and the other group}

In this experiment, you are randomly paired with 5 other participants. You and these other participants form a 6-person group, called your group. You will be in the same group in every round of the experiment. Your group is randomly matched with another group of the same size, called the other group. Your group and the same other group will be paired together in every round of the experiment.

\section{Overview of the experiment}

The experiment consists of multiple rounds. Each round follows the same procedure:

1. Your group will solve a task together, a so-called knapsack problem. To find the best solution to this problem, you can communicate with the other members of your group via a chatbox. The other group will solve the same knapsack problem under exactly the same circumstances as you.

2. After your group is done with the task, your group will receive points for your solution, depending on how close you were to the optimal solution. The other group will also receive points for their solution. Then, the computer will compare your group's points with those of the other group, to determine part of your earnings in this experiment.

3. You will be asked to estimate the percent chance that your group has more points than the other group in that round.

4. You will receive a clue about the relative performance of your group in that round.

5. You will participate in a market activity. In this market, you can trade (buy and sell) units of an asset with the other members of your group. The value of the asset depends on whether your group or the other group obtained more points in that round.

6. You will be asked, once more, to estimate the percent chance that your group has more points than the other group in that round.

Every round will proceed through these 6 parts. In every round, your group will solve a new knapsack problem. Therefore, your group's points (and those of the other group) are likely to vary across rounds. Everything else stays consistent across rounds.

\section{Your compensation}

You will be paid for your performance on the task, for your estimates of the percent chance that your group has more points than the other group, and for your profits in the market.

Earnings from task performance: Each group receives an initial endowment of $150 \mathrm{CHF}$. At the end of the experiment, one round will be randomly selected. Each round has the same probability to be selected. For this round, the computer will compare the points obtained by your group and the points obtained by the other group. The program will then transfer $90 \mathrm{CHF}$ from the endowment of the group with fewer points to the group with more points. If both groups have the same number of points, the receiver of the transfer is the group that took less time to find their solution.

Thus, the final endowment from the task of the group with fewer points will be $60 \mathrm{CHF}$ and the final endowment of the group with more points will be $240 \mathrm{CHF}$. The final 
endowment of your group will then be paid in equal shares to each member at the end of the experiment. So, if your group has more points than the other group, you will receive $240 \mathrm{CHF} / 6=40 \mathrm{CHF}$, and if your group has fewer points, you will receive $60 \mathrm{CHF} / 6=10$ CHF.

Earnings from the estimates: The computer will also randomly select another, different round, and will randomly select one of your two estimates in this round. Each of your estimates, other than the ones in the round selected by the computer to count for earnings from task performance, is equally likely to be chosen. The computer will also determine a payment based on the accuracy of your estimates. We will explain later, in detail, how this payment is determined.

Earnings from the market activity: The computer will also randomly select a third, different round. Each round, other than the rounds selected by the computer to count for earnings from task performance and for earnings from the estimates, is equally likely to be chosen. You will receive an additional payment based on the outcome of the market activity in this round. We will explain later, in detail, how the earnings from the market activity are determined.

We will now explain the experiment in more detail. 


\section{The knapsack problem}

A knapsack problem is a puzzle where a knapsack needs to be filled with a selection from among a number of items. Each item has a weight and a value. The knapsack has a weight capacity. You can choose to put items in the knapsack, up to the weight capacity of the knapsack. Your group's goal is to maximize the total value (sum of values) of the items that can fit in the knapsack.

Example 1: Here is an example of a simple knapsack problem. There are three items with the following weights and values.

\begin{tabular}{ccc}
\hline & Weight & Value \\
\hline $\mathbf{1}$ & 3 & 10 \\
$\mathbf{2}$ & 2 & 6 \\
$\mathbf{3}$ & 4 & 11 \\
\hline
\end{tabular}

The weight capacity (maximum weight) of the knapsack in this example is 6 . We can try all combinations, determine whether they fit, and if so, we should pick the best one.

\begin{tabular}{llll}
\hline $\begin{array}{l}\text { Items } \\
\text { “in" }\end{array}$ & $\begin{array}{l}\text { Total } \\
\text { Weight }\end{array}$ & $\begin{array}{l}\text { Fits? } \\
(\leq \mathbf{6})\end{array}$ & $\begin{array}{l}\text { Total } \\
\text { Value }\end{array}$ \\
\hline $\mathbf{1}$ & 3 & Yes & 10 \\
$\mathbf{2}$ & 2 & Yes & 6 \\
$\mathbf{3}$ & 4 & Yes & 11 \\
$\mathbf{1 , 2}$ & 5 & Yes & 16 \\
$\mathbf{1 , 3}$ & 7 & No & - \\
$\mathbf{2 , 3}$ & 6 & Yes & 17 \\
$\mathbf{1 , 2 , 3}$ & 9 & No & - \\
\hline
\end{tabular}

The best knapsack is obtained by choosing items 2 and 3 . This gives a total value of 17 $(=6+11)$ and a total weight of $6(=2+4)$.

\section{How your group's points are determined}

In each round, your group will work together on a knapsack problem. At the end of the round, your group's points equal the value of the best knapsack found by your group. The best knapsack is the knapsack with the most value that your group finds in that round. Remember that your group's points (and those of the other group) will determine your earnings from the task.

In each round, your group will first see the specific knapsack problem, and will get 90 seconds to discuss how to tackle this task using the chatbox. After that, your group will get another 60 seconds to work on the knapsack problem, while still having access to the chatbox. During that time, you can fill your knapsack and share your knapsack solutions with the group.

\section{Filling your knapsack}

Please look now at the separate sheet "Handout: overview knapsack screen." For the moment, only look at Panel A (in green) and Panel B (in blue). Here you can see how the knapsack problem from the above example would be displayed on your screen. The weight capacity is displayed at the center of Panel A. The upper-right corner of Panel A 
displays the time remaining. In the table in Panel B, you see the value and the weight of the items. By checking the checkbox below an item, you add this item to your knapsack. By checking the checkbox again, you delete this item from your knapsack. Note that during the 90-second interval during which your group can discuss how to tackle this task, you cannot add items to your knapsack. The total value and remaining capacity (capacity minus weight of the items already in the knapsack) of your current knapsack are displayed at the center of Panel B. The button "Share" will be explained later.

\section{Your group's best knapsack}

On your screen, you will always see the value, weight and content of your group's best knapsack. Remember, your group's best knapsack is the knapsack with the most value that your group has found so far. This is illustrated in Panel C (in red) in "Handout: overview knapsack screen." In this example, the best knapsack found so far in your group consists only of item 2 and has a value of 6 .

If you find a knapsack that has more value, you can click the "Share" button (in Panel B). Then, your group's best knapsack will be replaced by your current knapsack. The computer will only replace the previous best knapsack if your current knapsack has a higher value, and its weight is lower than (or equal to) the weight capacity. You can only submit your knapsack during the 60 -second work period.

Note that your knapsack will not be submitted automatically. Remember that your group's points in a round equal your group's best knapsack at the end of the work period. For your group to make progress, make sure to share your knapsack solutions whenever you find a better one.

\section{Communication}

Throughout the process, you can communicate through a chatbox. You can see the chatbox in Panel D (in orange) in "Handout: overview knapsack screen." You can write a message to the other members of your group by writing in the blue input field at the very bottom of the screen. Click the "Enter" Key to send the message. The identity of the group member sending a message will be represented by a number (1 through 6).

The "Share" button not only replaces the current best knapsack if your knapsack has a higher value; this button also allows you to communicate any solutions you want to share. When you click the "Share" button, your current knapsack (value, weight and content) will be posted in the chatbox, so the other members of your group can see your knapsack. The following message will appear in the chatbox: "I found a knapsack with value of [VALUE] and weight [WEIGHT]. I have the following items in my knapsack: [CONTENT]." The computer will only allow you to share your knapsack if its weight is lower than (or equal to) the weight capacity.

\section{Trial period}

Before proceeding with the rest of the instructions, you will have some time to familiarize yourself with the computer interface that you will use to solve knapsack problems and communicate with your group. For this purpose, you will see a trial knapsack problem on your screen, and you will have 90 seconds to test how the interface works. This trial has no influence on your earnings. During the trial, you cannot communicate with the other members of your team, but you can enter messages in the chatbox to see how they will appear.

If you have any questions during this trial period, please raise your hand and wait for a staff member to come and help you. 


\section{Estimate of relative performance}

Remember that in every round of the experiment, after your group works on a solution to the knapsack problem, you will provide an estimate of the percent chance that your group has more points in that round than the other group. You will enter the estimate by typing a number into an input box. You can enter any number between 0 percent and 100 percent. To give some examples of what these percentages mean:

- $\mathbf{5 0}$ percent means that you think it is equally likely that your group has fewer or more points than the other group,

- 0 percent means that you are certain that your group has fewer points than the other group, and

- 100 percent means that you are certain that your group has more points than the other group.

\section{How does accuracy determine the earnings from the estimates?}

We will now explain to you in detail how your estimates will influence your earnings in this experiment. As explained before, at the end of the experiment one of your estimates will be randomly selected and your payment will be determined according to the accuracy of this estimate. Lets call your estimate of the percent chance that your group has more points than the other group, $p$. Your payment depends on this estimate and on whether your group actually has fewer or more points in the selected round:

If your group has more points: If your group has fewer points:

$$
\begin{aligned}
& \text { Earnings }(\text { in } C H F)=10-10 *(1-p / 100)^{2} \\
& \text { Earnings }(\text { in } C H F)=10-10 *(p / 100)^{2}
\end{aligned}
$$

The range of your payoffs is from $0 \mathrm{CHF}$ to $10 \mathrm{CHF}$. These formulas may appear complicated, but what they mean for you is very simple: You can expect to earn the most money when you honestly report your best guess about the percent chance that your group has more points and avoid making estimates that are too high or too low. The following examples illustrate how these formulas make sure that you will earn more money by making more accurate estimates.

Example: Suppose that, at the end of the experiment, you learn that your group has more points than the other group in the chosen round.

- Suppose your estimate was $p=60$ percent. Then your earnings are $10-10 *(1-60 / 100)^{2} \mathrm{CHF}=8.4 \mathrm{CHF}$.

- Suppose your estimate was $p=40$ percent. Then your earnings are $10-10 *(1-40 / 100)^{2} \mathrm{CHF}=6.4 \mathrm{CHF}$.

Suppose that, at the end of the experiment, you learn that your group has fewer points than the other group in the chosen round.

- Suppose your estimate was $p=60$ percent. Then your earnings are $10-10 *(60 / 100)^{2} \mathrm{CHF}=6.4 \mathrm{CHF}$.

- Suppose your estimate was $p=40$ percent. Then your earnings are $10-10 *(40 / 100)^{2} \mathrm{CHF}=8.4 \mathrm{CHF}$.

Note that making an estimate that is too extreme-of either 0 percent or 100 percentcan earn you $10 \mathrm{CHF}$ if you are right, but will earn you $0 \mathrm{CHF}$ if you are wrong.

If both groups have the same number of points in a round, then the group that used less time to find their solution is considered to have "more points." 


\section{Clues about relative performance}

In every round, after you indicate your estimate the first time, you will then receive a clue about whether or not your group has more points than the other group in that round.

\section{What is a clue about relative performance?}

The clue informs you about your group's relative performance. Specifically, it gives you an indication about whether your group has fewer or more points in that round, to help you estimate the percent chance that your group has more points. However, the clue does not perfectly reveal which group did better.

In the following, we explain how the clue is generated:

- There is an Urn with 3 balls, determined as follows:

- 2 balls correspond to the group with more points, and

- 1 ball corresponds to the group with fewer points.

- The computer will randomly draw one ball out of the urn. Thus, each ball has the same chance to be drawn, namely $1 / 3$.

- The computer will tell every member of your group whether the drawn ball corresponds to your group or to the other group. Every member of your group will receive the same clue.

Note that this procedure means that a ball corresponding to the group that actually has more points has a $2 / 3$ chance to be selected, while a ball corresponding to the group that has fewer points has a $1 / 3$ chance to be selected. After you receive this clue, you again have to estimate the percent chance that your group has more points than the other group.

Note that the urn is newly filled after every round, according to the points received by your group and the points received by the other group in the knapsack problem in that round. 


\section{Market Instructions}

In every round, after your group has received the clue for that round, you will participate in a market in which you can trade assets. The market participants consist of the 6 members of your group.

In every market round you can sell and buy assets. At the beginning of every market round, you will receive an initial stock of assets, and an initial stock of cash. At the end of the round, you will be required to repay a part of the received stock of cash, the loan, from your market gains (and, if your market gains are not sufficient, from your other earnings from this experiment.)

Assets and cash stocks from the market are not transferred to the next round. That is, in each round you start with a new stock of assets and cash. The stock of new assets and cash you receive is independent of your stocks of assets and cash at the end of previous rounds and of any decisions you make in previous rounds.

\section{The asset and dividend}

At the end of each market round, every unit of the asset you own pays a dividend. The dividend depends on the number of points obtained by your group and the number of points obtained by the other group in the knapsack problem in that round. Specifically, if your group has more points than the other group in that round, the dividend from every unit of the asset equals 200 Rappen ( $2 \mathrm{CHF}$ ). If your group has fewer points than the other group in that round, the dividend equals 0 Rappen ( $0 \mathrm{CHF}$ ). The dividend is summarized in the following table:

\begin{tabular}{|l|c|}
\hline & Dividend per unit \\
\hline Your group has more points & 200 Rappen (2 CHF) \\
\hline Your group has less points & 0 Rappen (0 CHF) \\
\hline
\end{tabular}

Example: Suppose that a participant has an initial stock of 2 units of the asset. He or she buys 1 more unit in the course of the market activity. Therefore, after the market closes the participant owns 3 units of the asset. If that participant's group obtained more points than the other group in that round, the participant will receive a total dividend of $3 * 200$ Rappen $=600$ Rappen $(6 \mathrm{CHF})$. However, if the participant's group has fewer points, the participant will receive a total dividend of $3 * 0$ Rappen $=0$ Rappen (0 CHF).

\section{Negative asset stocks and short selling}

You will not be able to buy assets unless you have sufficient cash to pay the price. However, you will be able to sell units of the asset even if you do not currently own any units. In this case, your stock of assets in that round will become negative. This is called short selling.

If you sell a unit of the asset that you do not own, then you get to keep the sales price, but you will have to pay the dividend of this asset. That is, for every unit of the asset that you are short, 200 Rappen (2 CHF) will be subtracted from your earnings at the end of the market period if your group has more points, but 0 Rappen $(0 \mathrm{CHF})$ will be subtracted if 
your group has fewer points.

Note that you also might directly start a market round with a negative stock of assets.

There are constraints on how negative your stock of assets can become; that is, on how many units you can short sell. The computer will not allow you to submit orders that, if executed, are likely to generate losses of more than the initial loan you received. This will be discussed in detail later.

\section{How does the market work?}

Each participant in the market can buy and sell units of the asset. Each trading period automatically terminates after four minutes. During this time, each trader can submit offers to buy or sell, accept offers to buy or sell, and delete offers:

- Entering an offer: You can make an offer to sell or buy one unit at a specific price. Each offer consists of a price at which you are willing to buy or sell one unit of the asset. You may submit multiple offers to buy or sell the asset.

- Accepting an offer: You can also see a list of all the outstanding offers to buy and sell that other traders have entered in the market. By simply clicking a button, you can accept the best current offer to either buy or sell. That is:

- You can accept the current offer to buy with the highest price; in this case, you sell one unit of the asset at this price, or

- You can accept the current offer to sell with the lowest price; in this case, you buy one unit of the asset at this price.

If an offer is accepted, 1 unit of the asset is transferred from the seller to the buyer, and the trade price is transferred from the buyer to the seller.

- Delete offers: You can always delete any of your own outstanding offers.

Please look now at the separate sheet "Handout: overview market screen." This handout illustrates the market screen. The screen shows you three different panels. The yellow panel on the right indicates where you can enter your choices and see information that is relevant if you want to buy a unit of the asset. The green panel in the middle indicates where you can enter your choices and see information that is relevant if you want to sell a unit of the asset. Note that the top box in each panel is where you enter an offer, the middle box is where you accept an offer made by someone else, and the bottom box is where you see all the current offers and can delete any of your current offers.

The market screen also reports, in the panel on the left, a list of the trade prices of all previous trades in that market round and a graph showing these trade prices over time.

\section{Restrictions on offers}

The computer will prevent you from submitting any offer that, if accepted, would leave you with a negative cash balance. The computer will also prevent you from submitting any offer or making any trade that potentially generates losses of more than the initial loan you received. The computer will also delete any previous offer you have made if it becomes the case that completing these offers would put you in these situations. However, keep in mind that your earnings from a market round can be negative, in which case your losses will be subtracted from your earnings in other parts of the experiment.

The computer will also prevent you from submitting offers that do not improve on existing buy and sell offers. That is, the price of a new offer to buy must be higher than the highest 
price of all current offers to buy and the price of a new offer to sell must be lower than the lowest price of all current offers to sell.

\section{How your earnings from the market are computed}

As explained before, at the end of the experiment one of the rounds will be randomly selected and you will receive a payment equal to your earnings from that market round. To determine your earnings in a market round, there are three values that are important: the number of units of the asset that you own when the market rounds ends, the amount of cash you own when the market round ends, and the amount of any loan you received at the beginning of the market round.

Your earnings from the market are then (in Rappen):

\section{Units of asset * dividend + Cash - Loan}

That is, your earnings equal the total dividends from the assets you own and your remaining cash after you repay any loan with which you started the round. As explained earlier, the dividend paid by the asset depends on the relative performance of your group:

So, if your group has more points your earnings are: Units of asset $* 200+$ Cash - Loan And if your group has fewer points your earnings are: Cash - Loan

\section{What happens if the stock of assets you own is negative?}

Remember that you can have a negative stock of assets in a market round. If this is the case at the end of a round, then, you will have to pay the dividend for every unit of the asset below zero that you own. Thus, if your group has more points in that round, Units of asset * 200, will be a negative number and you will lose 200 Rappen (2 CHF) for every unit that your balance is below zero. Note that your earnings are calculated in exactly the same way, but the sign of Units of asset is now negative.

\section{What happens if your earnings are negative?}

If your earnings in the market round selected to count are positive, we will add them to your total earnings from this experiment. If your earnings are negative, we will subtract your loss from your total earnings from this experiment.

Examples:

1. Suppose a round is drawn in which you hold 3 units of the asset and 300 Rappen in cash at the end of the market round, and your initial loan was 700 Rappen.

- Earnings if your group has more points: $3 * 200+300-700=200$ Rappen (2 CHF).

- Earnings if your group has fewer points: $300-700=-400$ Rappen $(-4 \mathrm{CHF})$.

2. Suppose a period is drawn in which you hold -3 units of the asset and 900

Rappen in cash at the end of the market round, and your initial loan was 500

Rappen.

- Earnings if your group has more points: $-3 * 200+900-500=-200$ Rappen $(-2$

CHF).

- Earnings if your group has less points: $900-500=400$ Rappen (4 CHF). 


\section{Trial market round}

Before we start with the experiment, you will have an opportunity to familiarize yourself with the market through a trial market round. The trial market will work very similarly to how the market will work during the experiment, with three differences:

- The dividend in the trial market depends on a coin flip that the computer will conduct after the trial market round. If the outcome is tails the dividend is 200 Rappen (2 CHF), if the outcome is heads the dividend is 0 Rappen (0 CHF).

- You will participate in the trial market round with 5 other randomly matched participants. You are therefore not matched with your group and these are likely different participants than those with whom you will interact subsequently.

- This trial market round has no influence on your earnings from this experiment. However, it presents an opportunity to learn how to use the market, so it is a good idea to try to make as much money as you can.

Once you are ready to proceed to the trial period, please click "OK" on your screen. If you have any questions during this trial period, please raise your hand and wait for a staff member to come and help you. 


\section{Handout: overview knapsack screen}

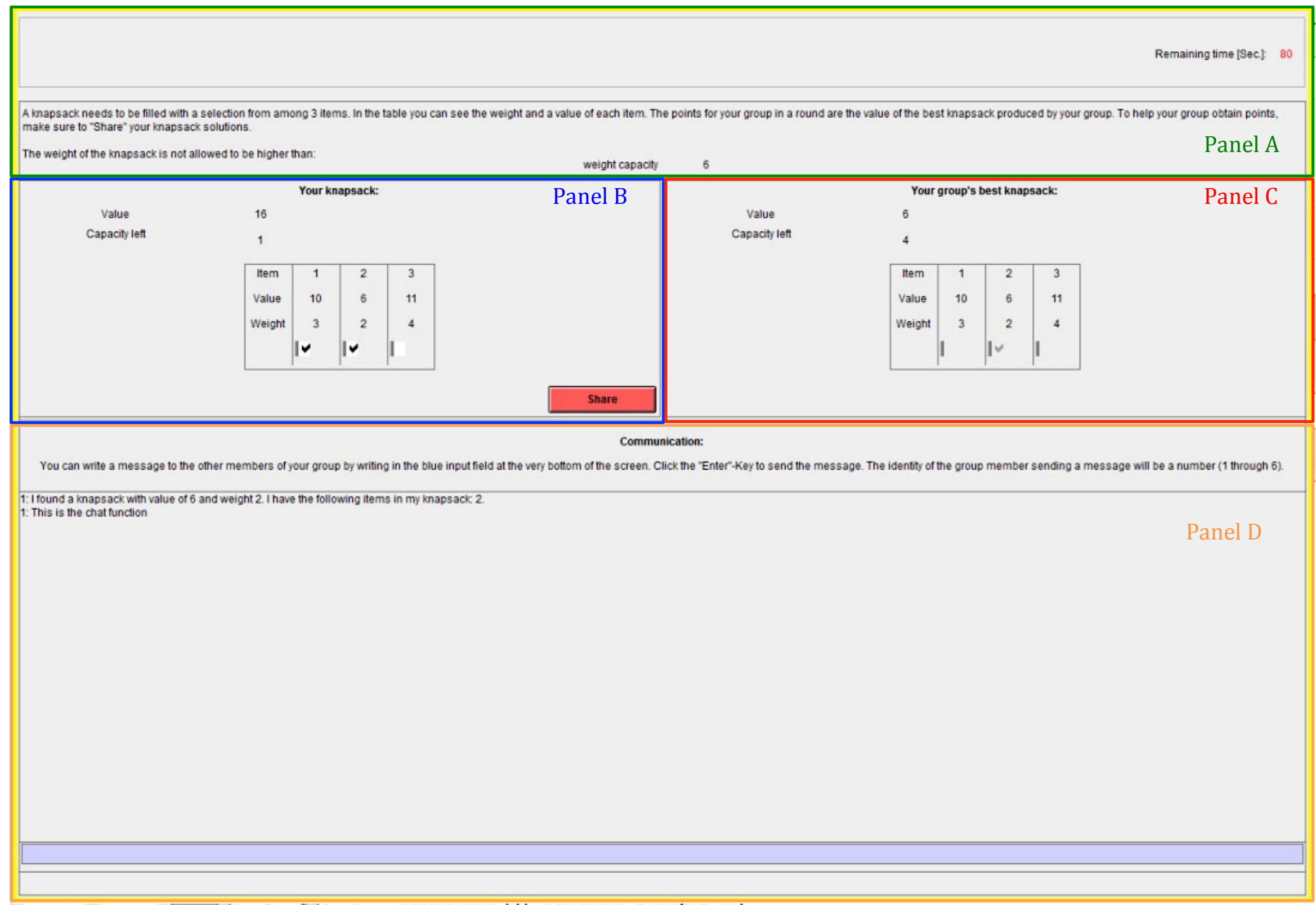




\section{Handout: overview market screen}

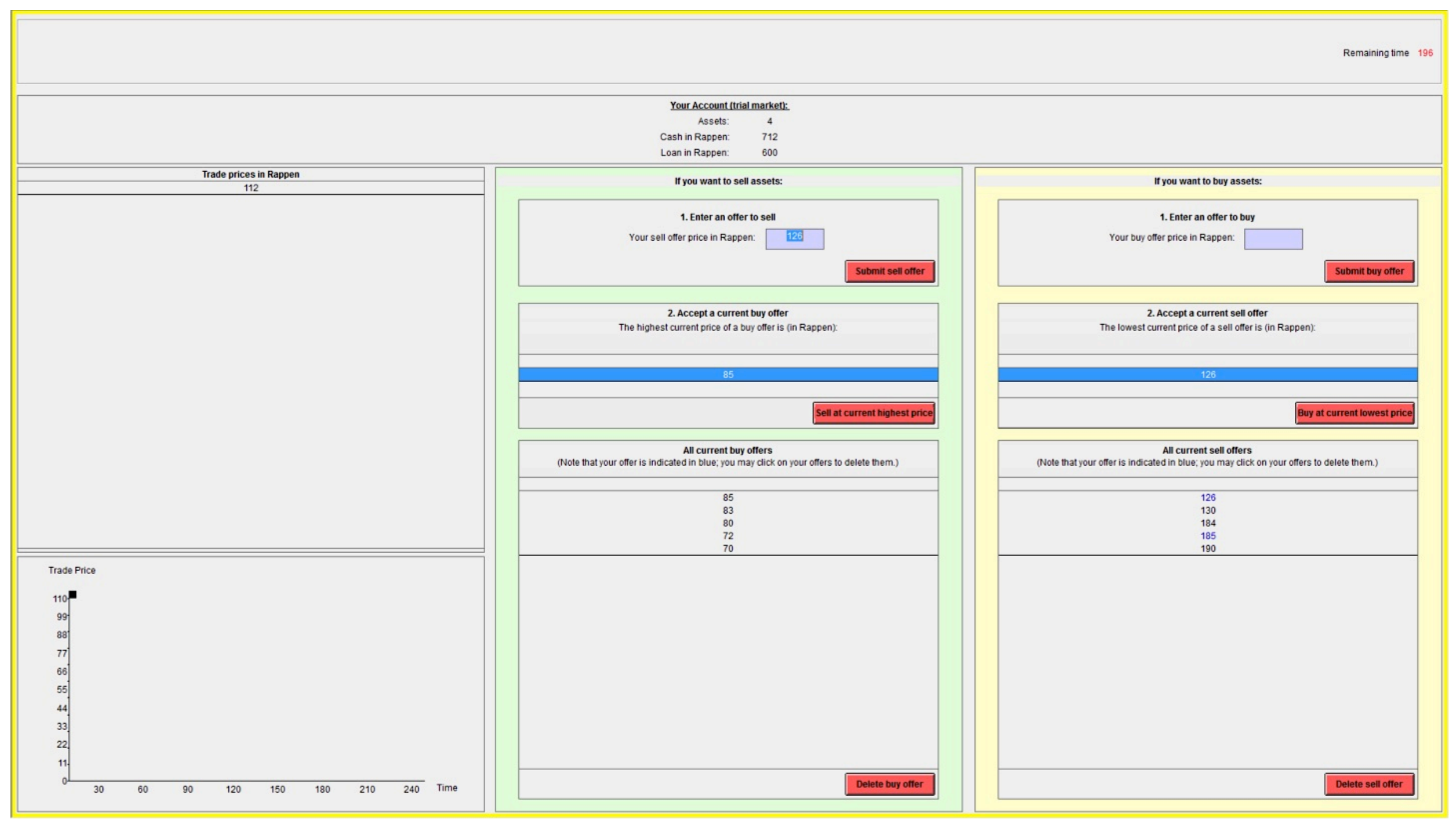

